\title{
Identification of a locus control region in the immunoglobulin heavy-chain locus that deregulates c-myc expression in plasmacytoma and Burkitt's
lymphoma cells
}

\author{
Linda Madisen ${ }^{1,2}$ and Mark Groudine ${ }^{1,2,3}$ \\ ${ }^{1}$ Hutchinson Cancer Center and Departments of ${ }^{2}$ Pathology and ${ }^{3}$ Radiation Oncology, University of Washington School of \\ Medicine, Seattle, Washington 98104 USA
}

In murine plasmacytoma and human Burkitt's lymphoma cells, one allele of c-myc is translocated into one of the immunoglobulin loci, resulting in a characteristic pattern of deregulated c-myc transcription.

Translocation events between c-myc and the IgH locus segregate c-myc and the IgH intron enhancer to different reciprocal products in all plasmacytomas and in most Burkitt's lymphoma cells, suggesting that an additional element(s) capable of affecting c-myc expression over a large and variable distance must exist in the IgH locus. The region 3' of the IgH C $\alpha$ gene contains four tissue-specific and cell stage-specific DNase I hypersensitive sites (HSs), two of which map to the late B cell-specific 3' $\mathrm{C} \alpha$ enhancer. We report here that DNA sequences comprising the two other $3^{\prime} \mathrm{C} \alpha$ HSs contain potential protein-binding motifs for trans-activators commonly associated with immunoglobulin enhancers and that these sites can function as cell stage-specific enhancers in transient B cell assays. A DNA fragment containing all four HSs (HS1234) synergistically activates c-myc transcription in plasmacytoma and Burkitt's lymphoma cells in transient assays and induces high-level transcription, a promoter shift from P2 to P1, and an increase in readthrough transcription in stable transfections. Furthermore, plasmacytoma clones stably transfected with a HS1234-linked c-myc construct express c-myc in a position-independent, copy number-dependent manner. These results suggest that HS1234 may function as a locus control region (LCR), deregulating c-myc expression in $t(15 ; 12)$ plasmacytomas, as well as potentially contributing to aspects of normal IgH chain expression.

[Key Words: IgH transcription; c-myc; Burkitt's lymphoma; LCR]

Received July 6, 1994; revised version accepted July 29, 1994.

In human Burkitt's lymphomas and murine plasmacytomas, one c-myc allele becomes juxtaposed to immunoglobulin sequences through a reciprocal $5^{\prime} \rightarrow 5^{\prime}$ chromosomal translocation (for review, see Cory 1986; Magrath 1990; Spencer and Groudine 1991). The rearranged c-myc allele is transcriptionally active in these cell types, whereas the germ-line c-myc allele is silenced, as it is in normal mature B cells (Bernard et al. 1983; Nishikura et al. 1983). In addition, c-myc promoter usage and transcriptional elongation are altered in those translocations in which the first c-myc exon remains intact (Taub et al. 1984; Denny et al. 1985; Bentley and Groudine 1986; Eick and Bornkamm 1989). These observations have led to the hypothesis that sequences present in the immunoglobulin locus that become linked to c-myc by translocation maintain c-myc expression and influence $c-m y c$ initiation and transcription in these cells. In translocations between c-myc and the immuno- globulin heavy-chain locus [human $t(8 ; 14)$ and mouse $t(15 ; 12)]$, the breakpoints involved on both chromosomes are highly variable. As a result, the well-described immunoglobulin heavy chain intron enhancer, $E \mu$, becomes linked in cis to c-myc only in about half of Burkitt's lymphomas and in none of the described murine plasmacytomas (Cory 1986), suggesting the presence of an additional sequence(s) in the immunoglobulin locus capable of driving c-myc expression. Further evidence for the presence of immunoglobulin heavy-chain regulatory sequences besides $\mathrm{E} \mu$ include the identification of mouse myeloma cell lines that produce functional $\mathrm{IgH}$ despite having deleted $\mathrm{E}_{\mu}$ (Klein et al. 1984; Aguilera et al. 1985; Eckhardt and Birshtein 1985). In addition, a natural deletion of sequences $3^{\prime}$ to the $\mathrm{C} \alpha$ gene has been shown to reduce IgH transcription in a line that retains $\mathrm{E} \mu$ (Gregor and Morrison 1986).

Recently, a late B cell-specific transcriptional en- 
hancer has been identified both in the rat (Pettersson et al. 1990) and the mouse IgH loci (Dariavach et al. 1991; Lieberson et al. 1991), located 25 and $16 \mathrm{~kb}$ downstream of the $\mathrm{C} \alpha$-coding region, respectively (3' $\mathrm{C} \alpha$ enhancer). Targeted deletion of this element in embryonic stem (ES) cells resulted in defects in germ-line transcription and secretion of specific immunoglobulin isotypes (Cogné et al. 1994). A third, less active enhancer in the IgH locus also has been identified immediately $3^{\prime}$ of the murine $\mathrm{C} \alpha$ gene (C $\alpha 3^{\prime}$ enhancer) (Matthias and Baltimore 1993).

Despite the strong transient enhancer activity reported for the rat $3^{\prime} \mathrm{C} \alpha$ enhancer in plasmacytomas (Pettersson et al. 1990), this enhancer had no significant effect on c-myc transcription in a stably transfected plasmacytoma line, MPC-11 (L. Madisen, unpubl.). Our search for additional regulatory elements in the $3^{\prime} \mathrm{Co}$ region that might deregulate the expression of translocated c-myc alleles has revealed a series of four tissuespecific and stage-specific DNase I hypersensitive sites (HSs) located $3^{\prime}$ of the $\mathrm{C} \alpha$-coding gene, consistent with the recent findings of Giannini et al. (1993). The two DNase I HSs most 5' in the series (HS1 and HS2, our nomenclature/ map to the $3^{\prime} \mathrm{C} \alpha$ enhancer, whereas two additional sites are located $\sim 13 \mathrm{~kb}$ (HS3) and $17 \mathrm{~kb}$ (HS4) farther $3^{\prime}$ of this enhancer.

The presence of these four tissue-specific and cell stage-specific DNase I sites is reminiscent of the locus control region (LCR) responsible for the tissue- and stage-specific expression of the $\beta$-like globin genes (Forrester et al. 1990; Townes and Behringer 1990). The $\beta$-globin LCR influences chromatin structure and timing of DNA replication over at least $200 \mathrm{~kb}$ and functions as a transcriptional enhancer over a distance of $\sim 75 \mathrm{~kb}$. In transfection and transgenic assays, the LCR confers tissue-specific, high-level and position-independent expression to cis-linked genes (Blom van Assendelft et al. 1989; Grosveld et al. 1987). These are characteristics that might be predicted for a regulatory element/domain in the IgH chain locus that effectively controls, over a large and variable distance, $c-m y c$ expression in $c-m y c / I g H$ translocations. Because the DNA region spanned by the four 3' $\mathrm{C} \alpha$ HSs is always linked to c-myc in plasmacytoma associated translocations, we wondered if these sites might play a role in controlling c-myc expression in these myelomas through an LCR-like mechanism.

In this report, we present the sequence of, and describe the enhancer activity associated with, DNA fragments comprising the two $3^{\prime}$-most distal IgH locus HSs mentioned above. Further, we show that a combination of the four DNase I HSs can affect c-myc transcription in stable transfections in Burkitt's lymphoma and plasmacytoma cell lines. Linkage of c-myc to a fragment containing HS1-4 resulted in a shift of c-myc promoter usage, from the $\mathrm{P} 2$ to the $\mathrm{P} 1$ promoter and increased the RNA polymerase density in $3^{\prime}$ regions of the gene. In addition, HS1-4 also conferred position-independent, copy number-dependent expression to linked c-myc genes stably integrated in a plasmacytoma cell line. In combination, these results suggest that the four DNase I HSs $3^{\prime}$ to C $\alpha$ may act as an LCR, deregulating c-myc expression in $t(15 ; 12)$ plasmacytomas, as well as potentially contributing to aspects of normal IgH chain expression such as isotype switching.

\section{Results}

\section{Chromatin and sequence analysis of the $3^{\prime} \mathrm{C} \alpha$ region}

Four tissue-specific and cell stage-specific DNase I HSs map to a region $\sim 10-30 \mathrm{~kb} \mathrm{3}$ ' of the $\mathrm{C} \alpha$-coding sequence in the mouse $\mathrm{IgH}$ locus. Figure $1 \mathrm{~A}$ depicts the relative location of these DNase I HS sites to the IgH intron enhancer and to various plasmacytoma breakpoints mapped in the IgH locus. HS1 and 2, (numbered for convenience $5^{\prime} \rightarrow 3^{\prime}$ ), lie within the previously described, late B cell-specific, 3' $\mathrm{C} \alpha$ enhancer. These sites, along with HS3, have been detected in DNA from a number of myeloma cell lines but are absent in DNA preparations from earlier stage B cells, including pre-B and LPS-induced pre-B cells, as well as from non-B cells, including $T$ cells, hematopoietic cells, and fibroblasts. The $3^{\prime}$-most distal site, HS4, has been detected in three pre-B lines tested and, to varying degrees, in different myeloma and plasmacytoma cells, but similar to the other three sites, is limited to cells of the B lineage (Fig. 1B,C; Giannini et al. 1993|. To evaluate whether these tissue- and cell stage-specific DNase I HSs comprise an LCR-like element in the IgH locus capable of affecting c-myc transcription, we cloned DNA regions encompassing each of these sites for use in transient and stable functional assays.

By Southern blot analysis, HS3 mapped to a 1182-bp $\mathrm{XbaI-Sau3A}$ fragment. The sequence of this fragment, shown in Figure 2A, contains homologies to many known protein-binding motifs, including a 7 of $8 \mathrm{bp}$ match to the octanucleotide element. Flanking the octamer-binding element are three exact matches to the $\mu \mathrm{E} 5$ site and close homologies to the $\mu \mathrm{E} 2$ - and $\mu \mathrm{E} 3$-binding motifs. These helix-loop-helix $\mathrm{E}$ box proteins have been shown to participate in controlling the specificity and activity of the IgH intron, $3^{\prime} \mathrm{K}$ and $3^{\prime} \mathrm{C} \alpha$ enhancers (Meyer and Neuberger 1989; Beckmann et al. 1990; Pongubala and Atchison 1991; Ruezinsky et al. 1991; Grant et al. 1992). In addition, good matches to the SV40 enhancer motifs AP-1, AP-2, and AP-4 are also present.

The 3'-most distal site, HS4, was similarly mapped to a 1381-bp PstI-HindIII fragment. The sequence of HS4 is shown in Figure 2B. As observed for the DNA fragment HS3, HS4 contains motifs associated with immunoglobulin enhancers. Of primary interest is the presence of two octanucleotide elements $/ 7 / 8$ and $8 / 8$ match to consensus) separated by $120 \mathrm{bp}$. HS4 also contains numerous sequence similarities to the $\mu \mathrm{E} 5$ consensus, as well as a single $\mu$ E3-like motif $\sim 420$ bp $3^{\prime}$ of the two octanucleotide elements. In addition, multiple sequence homologies to the AP-1, AP-2, and AP-4 SV40 enhancer sites are present.

Thus, DNA sequences that comprise HS3 and HS4 contain potential protein-binding motifs for many of the trans-activators known to regulate the $\mathrm{IgH}$ intron, $3^{\prime} \mathrm{C} \alpha$ 
A $>200 \mathrm{~kb}$

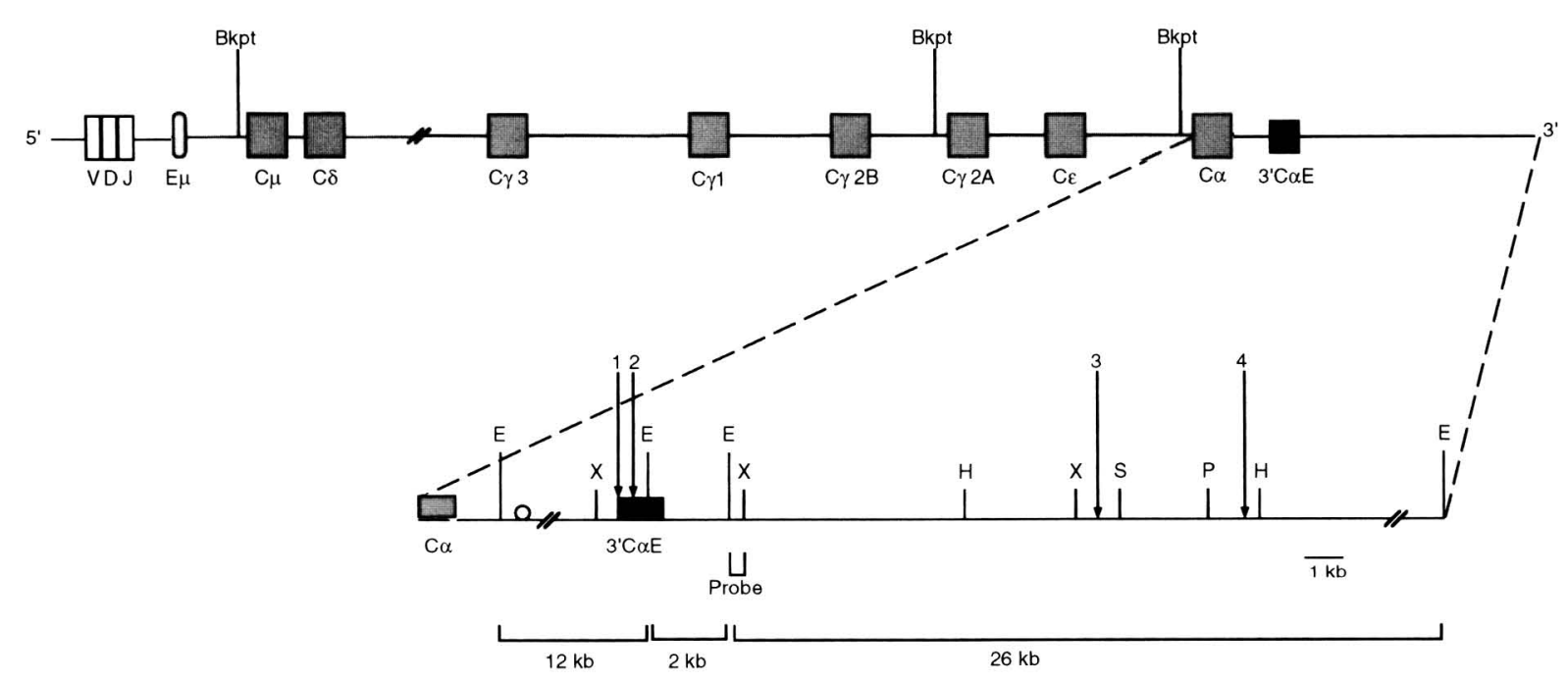

B

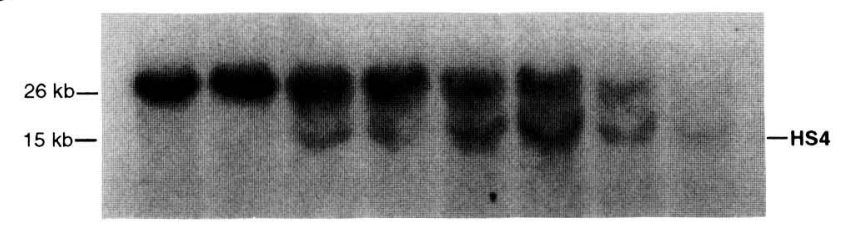

C

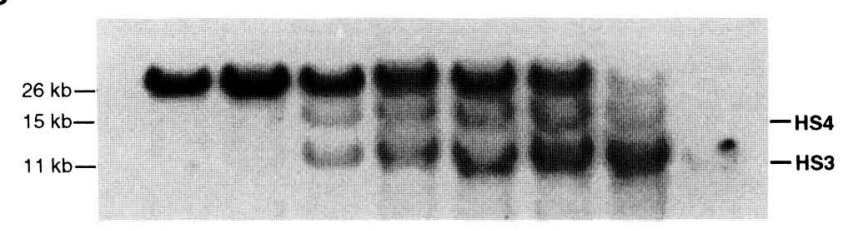

Figure 1. Location of tissue- and cell stage-specific DNase I HSs in the region $3^{\prime}$ of the murine IgH $3^{\prime}$ C $\alpha$ enhancer. (A) A schematic diagram of the murine $\mathrm{IgH}$ locus depicting the relative location of the IgH intron enhancer, $\mathrm{E} \mu$ (shaded oval), the $3^{\prime} \mathrm{C} \alpha$ regulatory region, containing $\mathrm{HS} 1-4$, and representative breakpoints mapped in various $t(15 ; 12)$ plasmacytomas. A magnified diagram of the 3 ' $\mathrm{C} \alpha$ region in 129 ES cells is also shown. Two sites (HS1, HS2) located within the 3' C $\alpha$ enhancer ( $\square$ ) are separated from HS3 and HS4 by $\sim 13$ and $17 \mathrm{~kb}$. (O) The C $\alpha 3^{\prime}$ enhancer. Only selected restriction sites are shown. (E) EcoRI; (X) XbaI; (H) HindIII; (S) Sau3A; (P) $P$ stI. $(B, C)$ Nuclei from different stage B cell lines were treated with increasing amounts of DNase I before isolation of genomic DNA (see Materials and methods). Southern blots of EcoRI-digested DNA from the pre-B line 18-81 and the late B plasmacytoma line MPC-11 were probed with a 500-bp EcoRI-XbaI fragment (indicated in A). This probe hybridizes to a unique EcoRI fragment of an approximate size of $26 \mathrm{~kb}$ in untreated EcoRI-digested DNA. In 18-81 DNA (B), a single subfragment of $15 \mathrm{~kb}$ (HS4) is seen in addition to the $26-\mathrm{kb}$ parental band, whereas MPC-11 DNA $(C)$ contains the $15-\mathrm{kb}$ subfragment (HS4) along with a more prominent $11-\mathrm{kb}$ subband (HS3). Similar analysis of TEPC 1165 plasmacytoma DNA revealed identical subfragments as in $C$.

and $3^{\prime} \kappa$ light-chain enhancers. Although the functional significance of these motifs in HS3 and HS4 has not yet been demonstrated, the apparent clustering of binding sites for factors involved in immunoglobulin expression in these HS fragments may suggest a role for these sequences in heavy-chain gene expression.

\section{HS1-4 enhance promoter activity in transient assays in plasmacytoma cells}

To determine whether DNA fragments containing HS3 and HS4 represent elements that might contribute to a LCR function in c-myc deregulation, we first evaluated the ability of these DNA fragments to stimulate transient transcription of a reporter gene in various cell types. Sequences of DNA included in the four 3' C $\alpha$ HSs were cloned singly and in combinations upstream of the human growth hormone gene under the control of either the human c-myc promoter $(2.5-\mathrm{kb}$ HindIII-NaeI $)$ or the immunoglobulin light-chain promoter, $\mathrm{V} \lambda 1$ (Hagman et al. 1990) (Fig. 3A). The orientation of the various HSs relative to each other and to the promoter was chosen to reproduce that found in translocations involving c-myc and the immunoglobulin heavy-chain locus, that is, a $5^{\prime} \rightarrow 5^{\prime}$ orientation. As a comparison, we also analyzed the activity of a $1-\mathrm{kb} X b a \mathrm{I}$ fragment containing the enhancing and flanking matrix attachment region (MAR) sequences of mouse $\mathrm{E} \mu$ (Cockerill et al. 1987). The ability of the various HSs to enhance transcription from the c-myc and $V \lambda 1$ promoters in different cell types is shown in Figure 4 and summarized in Table 1.

Consistent with previous reports, the $3^{\prime} \mathrm{C} \alpha$ enhancer (HS12) increased transcription from both promoters 
A

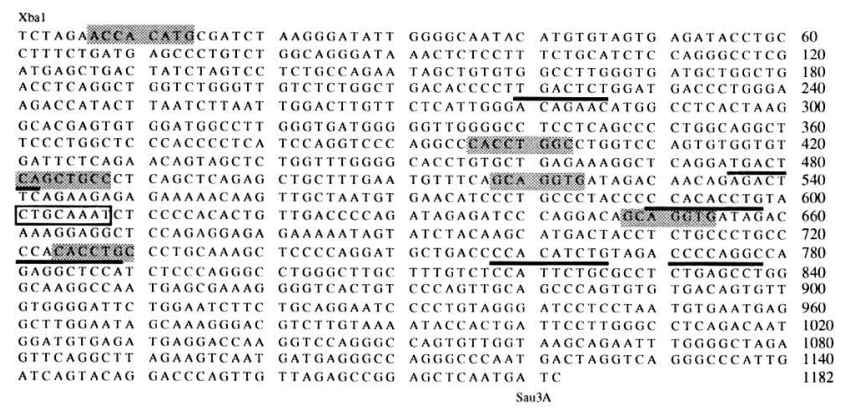

B

Psth

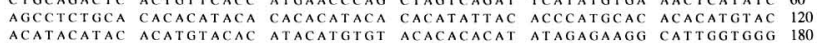
ACATACATAC ACATGTACAC ATACATGTGT ACACACACAT ATAGAGAGG CATGGTGGG 180
GAAACATTA GGCCATGGC ACAGTACAGG GCACAAGGAT GGTGGTACAG AATGAGGTCA 230

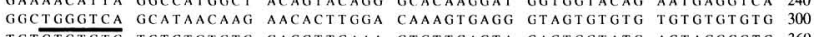

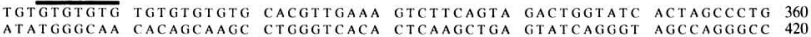

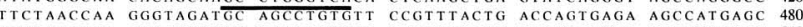

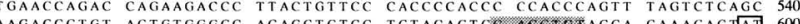

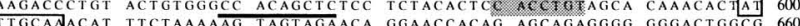

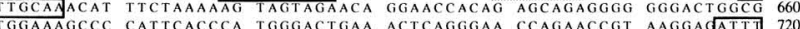

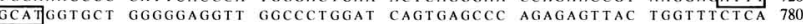
CITCCATCAT GTCACCTCC TCAACCCCA AAATGGCCA GGCCTAGGCT ATGGATGAGT 840
TTCAATGACC AGGCCCTAAG GACGAGTCAC AGAGGACTTC CTGGTGGGCT CAGGCAGCAO 9000

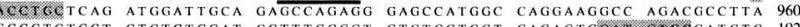
Fach CCCAAGAAG CAATCCCCAG CCTCAGGATC CACAACTACT TCCCCTACAG ACATGAGTGA 1140

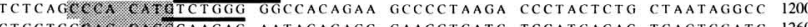

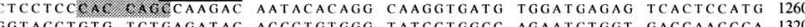

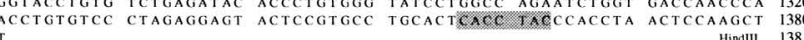
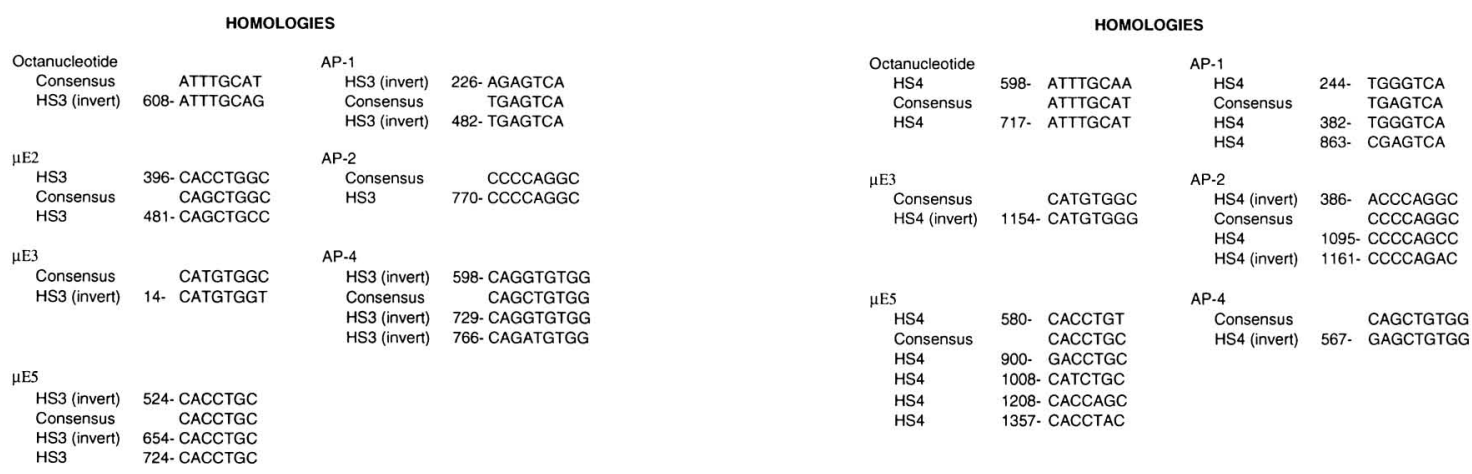

Figure 2. Nucleotide sequences of restriction fragments determined to contain HS3 and HS4. Southern blot mapping of the region surrounding HS3 and HS4 in MPC-11 cells led to the subcloning of a 1182-bp XbaI-Sau3A fragment containing HS3 $(A)$ and a 1381-bp PstI-HindIII fragment containing HS4 $(B)$ from a 129 ES genomic phage library. Representative sequence homologies to known protein-binding motifs are indicated by shading ( $\mu \mathrm{E} 2, \mu \mathrm{E} 3, \mu \mathrm{E} 5$ sites) and underlines (AP-1, AP-2, AP-4 sites). Homologies to the octamer element are boxed. Comparisons between HS3 and HS4 protein-binding motifs and their canonical sites are shown below each sequence.

tested in a late $B$ cell line, plasmacytoma TEPC 1165 (Fig. 4A,B). In TEPC 1165, the 3' C $\alpha$ enhancer increased growth hormone transcription from the c-myc promoter $>100$-fold, $\sim 10 \%$ of the activity shown by the $\mathrm{E} \mu$ enhancer. DNA fragments comprising HS3 or HS4 increased transcription from the c-myc promoter 40 -fold in the 1165 cells, approximately one-third the level of the 3' $\mathrm{C} \alpha$ enhancer. Significant activation of transcription, approximating that induced by the $\mathrm{E}_{\mu}$ enhancer, resulted when various combinations of the same HS-containing fragments were placed upstream of the c-myc promoter. The combination of HS1234 activated growth hormone transcription 1000-fold above an enhancerless control, suggesting a strong synergistic interaction between factors binding to these sites. Synergistic transcriptional activation was exhibited by other combinations of HS fragments as well. HS123-, HS124-, and HS34-containing constructs gave $710-, 270-$, and 520 -fold as much growth hormone, respectively, as the promoter only construct in 1165 cells. Constructs containing two copies of HS3 (HS3,3) or HS4 (HS4,4) exhibited synergistic transcriptional activation in 1165 cells, whereas an additive effect was seen with two copies of HS12 (HS12,12), the 3' C $\alpha$ enhancer. A similar pattern of c-myc promoter activa- tion was observed when the same constructs were transiently expressed in a second plasmacytoma cell line, MPC-11 (data not shown).

To determine whether the transcriptional enhancer activity associated with various HS-site combinations described above was specific to the c-myc promoter, we replaced the c-myc promoter in the growth hormone constructs with an immunoglobulin promoter $V \lambda 1$. Transient growth hormone assays with the $V \lambda 1$ constructs in 1165 plasmacytoma cells demonstrated that combinations of HS-containing fragments synergistically activated transcription in a pattern similar to that observed using the c-myc promoter (Fig. 4B; Table 1). Maximal activation of the $\mathrm{V} \lambda \mathrm{l}$ promoter, resulting in a 690-fold increase in reporter expression compared with an enhancerless construct, was observed with a construct containing HS1234 . DNA fragments containing combinations of HS123, HS124, and HS34 enhanced expression 220- to 340 -fold. As with the c-myc promoter constructs, HS12, HS3, and HS4 activated the Vג1 promoter constructs to a much lower extent when present individually. The ability of these individual sites to enhance $V \lambda l$ promoter transcription relative to each other differed from that observed with the c-myc promoter, 
Figure 3. Constructs used in transient and stable transfection assays to evaluate enhancer activity of $\mathrm{HSl}-4$. (A) For transient analyses, the $\mathrm{HGH}$ gene was placed under the control of either the human c-myc promoter (2.5-kb HindIII-NaeI fragment) or the immunoglobulin $\mathrm{V} \lambda \mathrm{l}$ promoter. DNA fragments containing $\mathrm{HS} 1-4$ were cloned singly and in various combinations upstream of the promoter in an orientation that reproduced that found in translocations between c-myc and the IgH locus, i.e., a $5^{\prime} \rightarrow 5^{\prime}$ orientation. DNA fragments used to represent the various HSs are indicated by boxes: HS12 (light gray shaded box) is a 4-kb XbaI fragment; HS3 (dark gray shaded box) is a $1.2-\mathrm{kb}$ XbaI-Sau3A fragment; HS4 (hatched box) is a 1.4-kb PstI-HindIII fragment. Construct names specify the HSs included in them. For comparison, constructs were also made in which a $1-\mathrm{kb} \mathrm{XbaI}$ fragment containing the murine IgH intron enhancer $(E \mu)$ was cloned upstream of the promoter. $(B)$ For stable analyses, some of the HS combinations described in $A$ were cloned upstream, in a $5^{\prime} \rightarrow 5^{\prime}$ orientation, of the full-length human c-myc-coding sequence (8.1-kb HindIII-EcoRI) in either a pBluescript vector (integrated stables) or a pHEBO vector (episomal stables). Details of constructs used in transfection studies are presented in Materials and methods.
A

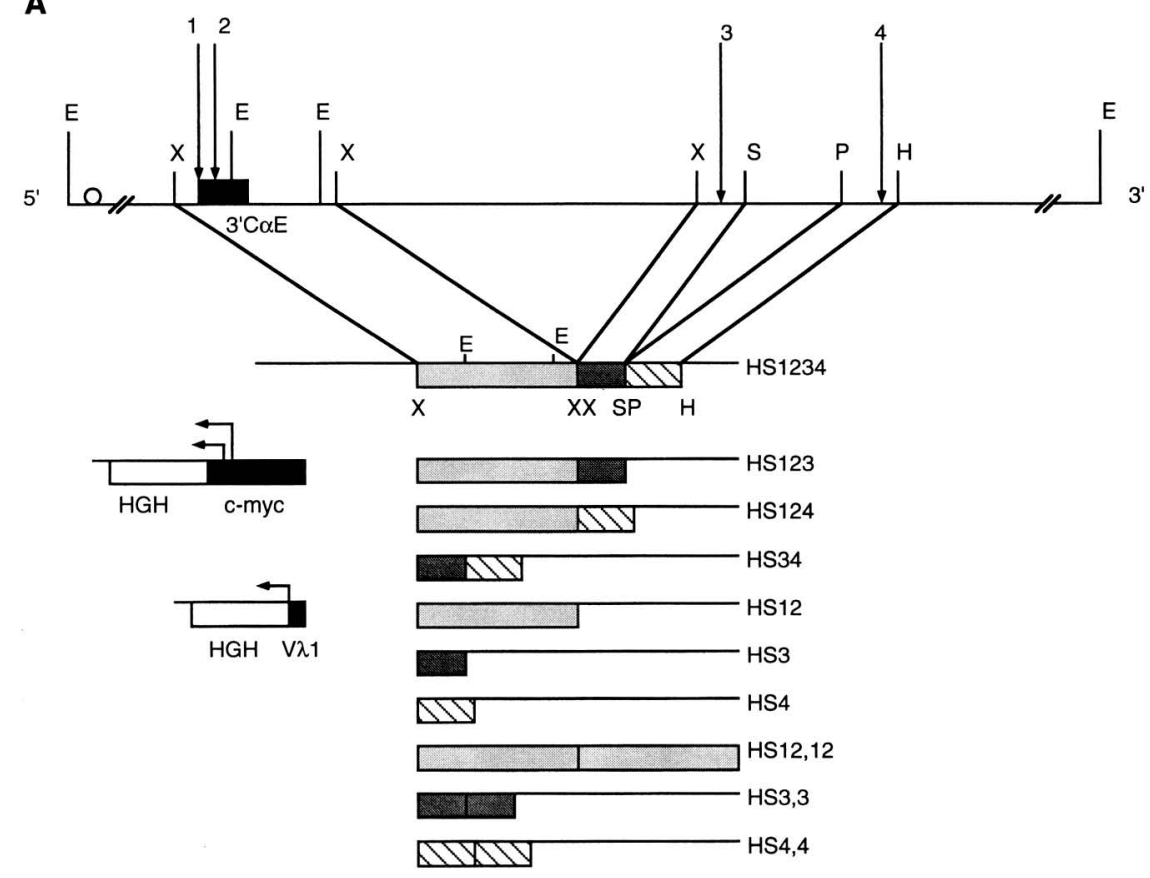

B

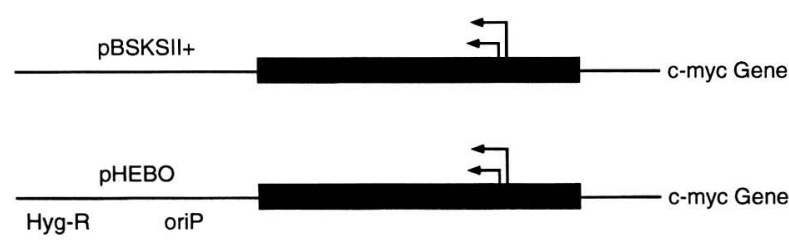

although combinations of HS sites clearly activated both promoters in 1165 cells in a synergistic fashion.

\section{$H S 4$, but not HS1-3, enhances activity in pre-B cells}

In the pre-B lymphocyte cell line $18-81$, only HS4 is hypersensitive to DNase I digestion (Fig. 1B). To determine whether HS4 is capable of enhancing transcription in pre-B cells, we repeated our transient transcription analysis in 18-81 cells. As shown in Figure 4C and summarized in Table 1, the DNA fragment containing HS4 does increase transcription from the c-myc promoter fourfold over the c-myc enhancerless control in 18-81 cells. A more dramatic enhancement of 30 -fold was observed with two copies of HS4, again indicating that HS4 can bind factors that synergize with each other to activate transcription. As might be expected from the DNase I mapping data, neither HS12 nor HS3 stimulated transcription in 18-81 cells, even when present in multiple copies. Combinations of HS124, HS34, and HS1234 stimulated growth hormone levels to that equaling HS4 alone.

In the pre-B 18-81 cell line, the enhancerless $V \lambda 1$ growth-hormone construct demonstrated low basal activity, and no significant increase in transcription was observed by addition of fragments containing only $\mathrm{HS} 12$ or HS3 (Fig. 4D and Table 1). In contrast, and as observed for the c-myc promoter, HS4 enhanced V $\lambda 1$ promoterdriven growth hormone levels equally well by itself and in combination with HS3 and HS123, increasing transcription 15-fold above an enhancerless control. The $\mathrm{V} \lambda \mathrm{l}$ promoter construct containing HS12 in addition to HS4, however, was only half as active as HS4 alone (8- vs. 15 -fold induction). The apparent inhibitory effect of HS12 on HS4 in 1881 cells was not observed in the c-myc promoter assays and may reflect a specific negative interaction between a protein binding to $\mathrm{HS} 12$ and the $\mathrm{V} \lambda \mathrm{l}$ promoter.

The enhancer activity of HS1-4 is specific to cells of the $B$ lineage

The B cell specificity of the HS1-4 enhancing fragments was investigated by determining their ability to stimulate growth hormone expression in L-cells, a mouse fibroblast cell line. Although the $\mathrm{V} \lambda 1$ promoter itself directed considerable transcription in these cells, none of the HS1-4 fragments increased this basal transcription (Fig. 4E; Table 1). Some repression of growth hormone expression was observed in constructs containing the 


\section{Plasmacytoma}

A

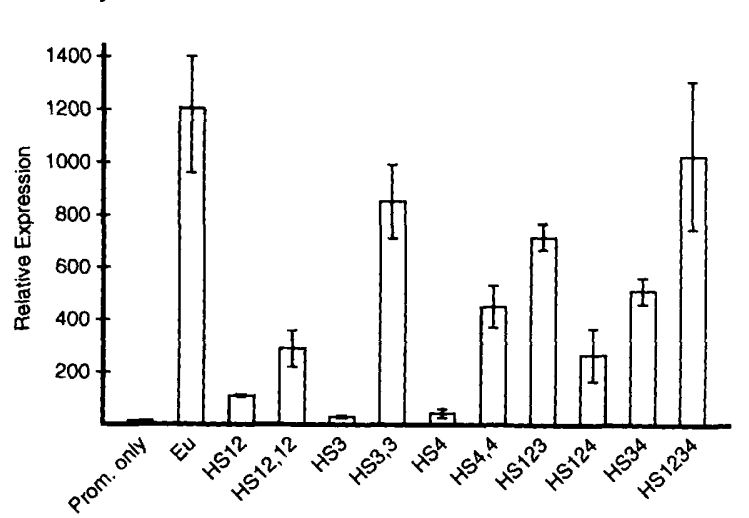

\section{8-81 Pre-B}

C c-myc Promoter

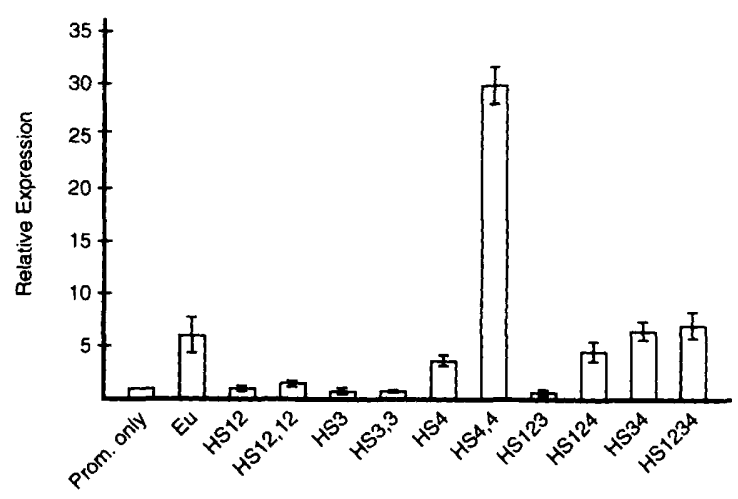

B Vג1 Promoter

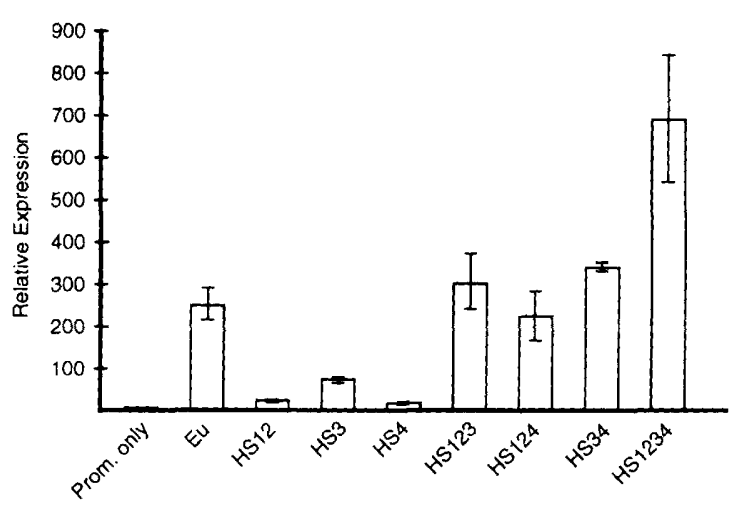

D V 1 Promoter

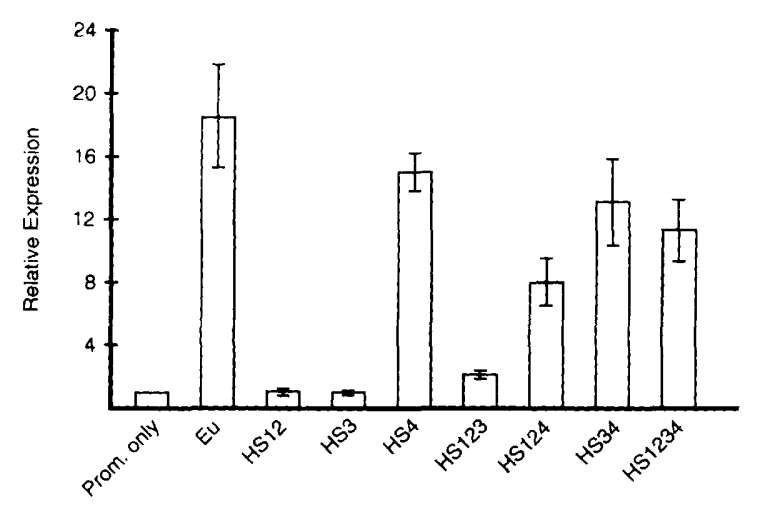

\section{L-cell Fibroblast}

E V $\lambda 1$ Promoter

Figure 4. Enhancer activity of $\mathrm{HS} 1-4$ in different cell backgrounds Cell lines were electroporated with test plasmid and a pCMV $\beta$-gal control as described in Materials and methods. After $48 \mathrm{hr}$, cell supernatants were assayed for growth hormone expression and pellets were assayed for $\beta$-gal content. Relative expression was determined by comparing $\beta$-gal normalized growth hormone levels induced by HS-containing plasmids with that by an enhancerless control (promoter only equals 1). Values represent the average and standard deviations of three to six transfections. The ability of various HS combinations to enhance transcription from the $c-m y c$ promoter was tested in the late $B$ plasmacytoma line TEPC $1165\langle A\rangle$ and in the pre-B 18-81 line $\langle C\rangle$. Transcriptional enhancement of the $\mathrm{V} \lambda \mathrm{l}$ promoter constructs was evaluated similarly in TEPC $1165(B)$ and $18-81(D)$ as well as in the mouse fibroblast $L$-cell line $(E)$. Results for each panel were graphed to best suit the particular data; therefore, scales on the $\mathrm{X}$-axis (Relative Expression/ vary significantly between panels.

various combinations of HSs. Similar results were obtained with the c-myc promoter and growth hormone constructs (data not shown).

In summary, the transient assays described above show that the tissue-specific and developmentally regulated DNase I HSs present in late B and pre-B cell lines define sequences capable of enhancing transcription in these cells. Synergistic interactions were observed in plasmacytoma cells when combinations of sites were present, whereas only HS4 appeared active at the pre-B developmental stage. No individual site or combination of sites demonstrated enhancing activity in a non-B cell, 
Table 1. Relative expression of $H G H$ by c-myc and $V \lambda 1$ promoters in different cell types

\begin{tabular}{|c|c|c|c|}
\hline & $\begin{array}{l}1165 \\
\text { Plasmacytoma } \\
\text { line }\end{array}$ & $\begin{array}{l}18-81 \\
\text { Pre-B line }\end{array}$ & $\begin{array}{l}\text { L-cell } \\
\text { fibroblasts }\end{array}$ \\
\hline \multicolumn{4}{|l|}{ c-Myc promoter } \\
\hline HS12 & $115 \pm 5$ & $0.8 \pm 0.2$ & \\
\hline HS3 & $38 \pm 5$ & $0.7 \pm 0.3$ & \\
\hline HS4 & $42 \pm 8$ & $3.6 \pm 0.5$ & \\
\hline HS 123 & $712 \pm 49$ & $0.7 \pm 0.2$ & \\
\hline HS 124 & $273 \pm 101$ & $4.6 \pm 0.9$ & \\
\hline HS34 & $516 \pm 47$ & $6.4 \pm 0.9$ & \\
\hline HS 1234 & $1020 \pm 280$ & $6.9 \pm 1.1$ & \\
\hline $\mathrm{HS} 12,12$ & $250 \pm 67$ & $1.6 \pm 0.3$ & \\
\hline HS3, 3 & $851 \pm 140$ & $0.7 \pm 0.1$ & \\
\hline HS4, 4 & $450 \pm 80$ & $29.8 \pm 1.7$ & \\
\hline $\mathrm{E}_{\mu}$ & $1203 \pm 211$ & $6.2 \pm 1.6$ & \\
\hline \multicolumn{4}{|l|}{$\mathrm{V} \lambda 1$ promoter } \\
\hline promoter only & 1 & 1 & 1 \\
\hline HS12 & $27 \pm 4$ & $1.1 \pm 0.2$ & $0.11 \pm 0.01$ \\
\hline HS3 & $75 \pm 6$ & $1.0 \pm 0.1$ & $0.62 \pm 0.05$ \\
\hline HS4 & $17 \pm 4$ & $15.0 \pm 1.4$ & $0.76 \pm 0.24$ \\
\hline HS123 & $303 \pm 65$ & $2.1 \pm 0.3$ & $0.08 \pm 0.01$ \\
\hline HS124 & $224 \pm 58$ & $8.0 \pm 1.5$ & $0.14 \pm 0.05$ \\
\hline HS34 & $338 \pm 10$ & $13.2 \pm 2.8$ & $0.19 \pm 0.03$ \\
\hline HS 1234 & $689 \pm 175$ & $11.4 \pm 1.9$ & $0.08 \pm 0.02$ \\
\hline $\mathrm{E} \mu$ & $247 \pm 38$ & $18.5 \pm 3.2$ & $0.30 \pm 0.02$ \\
\hline
\end{tabular}

consistent with the lack of detectable hypersensitivity in the $3^{\prime} \mathrm{C} \alpha$ region in these cells.

HS1-4 confer position-independent and copy numberdependent expression and a shift in promoter usage to a cis-linked c-myc gene in a plasmacytoma cell line

As discussed in the introductory section, reciprocal chromosomal translocations between a c-myc allele and one of the immunoglobulin loci results in the elevated, deregulated expression of the translocated allele in mature $B$ cells as well as an increase in usage of the normally minor promoter, Pl. When normal or mutated c-myc genes are transfected into mouse fibroblasts (Richman and Hayday 1989), B-lineage cells (Spencer et al. 1990), and human Burkitt's lymphoma cells (Polack et al. 1991), low expression initiating predominately from the P2 promoter is observed. In addition, few of the transfected genes are expressed, suggesting that the position of integration may influence the expression of these c-myc genes. Presumably then, sequences in the immunoglobulin locus that are juxtaposed to the translocated c-myc allele and that have not been included in the transfected c-myc constructs, are required to effect $\mathrm{c}-\mathrm{myc}$ deregulation. Our findings, in transient assays, of a synergistic activation of the c-myc promoter by HS1234 led us to examine whether these sequences could overcome position effects and deregulate c-myc expression in stable transfections.

1165 cells were co-transfected with RSV-neo and ei- ther c-myc or HS1234 c-myc (Fig. 3A,B), and individual clones were propagated following selection with G418. DNA copy numbers were determined by Southern blot analysis, and RNA expression was analyzed by S1 protection with end-labeled probes specific for human c-myc and mouse glyceraldehyde-3-phosphate dehydrogenase (GAPDH) transcripts. The expression of $c-m y c$ and HS1234 c-myc-containing 1165 clones is shown in Figure 5A. The transfected 1165 clones contained from 1 to 28 and 3 to 14 copies of c-myc and HS1234 c-myc, respectively (data not shown). Only one of eight clones positive for the control c-myc-transfected DNA showed detectable c-myc transcription (clone 1.2, having nine copies), whereas all 16 HS1234 c-myc-positive clones expressed high levels of human c-myc. This result suggests that the DNA fragment containing HS1234 is sufficient to confer position-independent expression to the linked $c-m y c$ gene. In addition, clones containing the HS1234 c-myc construct expressed the transfected c-myc gene in a copy number-dependent manner (Fig. 5B).

Cis linkage of HS1234 to c-myc also affected both the overall level of transfected gene expression and the ratio of P1- to P2-initiated transcripts. Total expression of P1and P2-initiated transcripts per copy of integrated DNA, relative to an internal control transcript (GAPDH), was 10- to 100-fold higher in clones containing HS1234 compared with clone 1.2 , with 12 of 16 clones demonstrating 20 - to 30 -fold higher expression per copy. In addition, 15/16 of the HS1234 c-myc clones demonstrated a P1/P2 ratio between 0.8 and 1.2 , whereas $c-m y c$ clone 1.2 showed a $\mathrm{P} 1 / \mathrm{P} 2$ ratio of 0.4 .

In summary, our findings in stably transfected 1165 plasmacytoma cells indicate that linkage of HS1234 to human c-myc results in enhanced c-myc transcription, distinguished by increased utilization of the normally minor $\mathrm{Pl}$ promoter and by apparent position-independent, copy number-dependent expression of the transfected gene. In combination, these results suggest that HS1234 comprise an LCR-like element that may be responsible for the deregulation of the translocated c-myc allele in plasmacytomas and Burkitt's lymphomas.

The activity of murine HS1-4 is conserved in a human Burkitt's lymphoma cell line

Because many of the aberrant features of c-myc expression observed in murine plasmacytomas and human Burkitt's lymphomas are similar, we were curious whether the murine $3^{\prime} \mathrm{C} \alpha \mathrm{HS} 1234$ could also influence c-myc transcription in a human Burkitt's lymphoma cell line. Transient expression assays performed in the EpsteinBarr virus-positive Raji Burkitt's lymphoma line with the c-myc growth-hormone constructs described above revealed that the activity of the mouse-derived HS fragments is conserved in the human Burkitt's lymphoma background. Transcription from the c-myc promoter was increased 11-fold by the addition of HS1234, whereas HS12 increased reporter gene expression only slightly in Raji cells, about twofold above an enhancerless control construct (data not shown). 
A

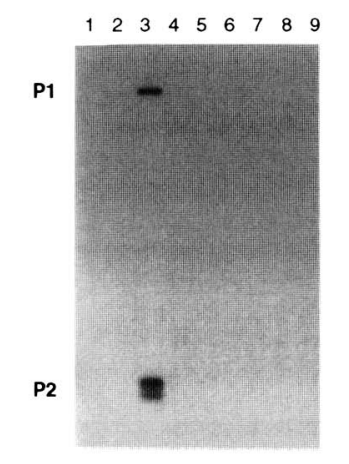

P2

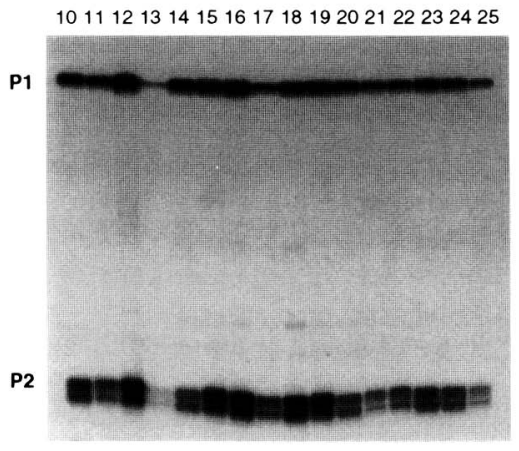

GAPDH

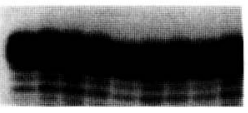

GAPDH

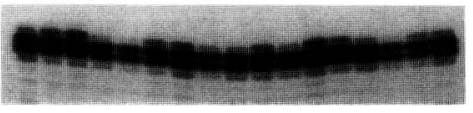

B

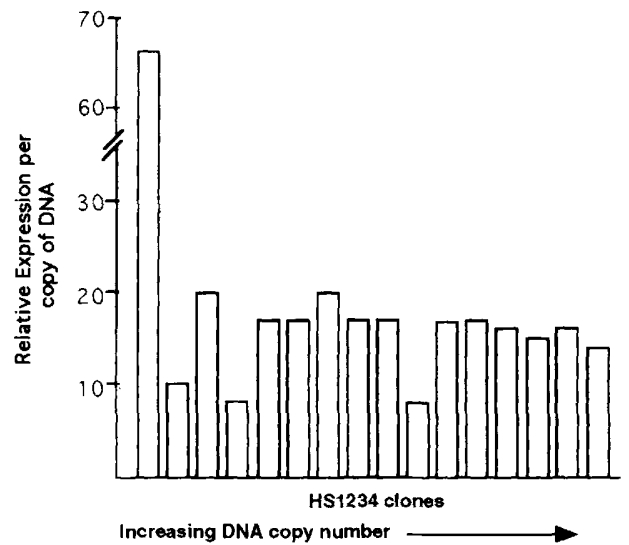

Figure 5. Expression of human c-myc and HS1234 linked human c-myc in mouse plasmacytoma 1165 cells. Total RNA isolated from stably transfected 1165 clones was analyzed in a S1 nuclease assay with end-labeled singlestranded probes specific for human c-myc and mouse GAPDH. A diagram of the human $c-m y c$ probe and the sizes of protected fragments corresponding to P1- and P2initiated c-myc transcripts are shown. (A) S1 mapping of RNA from untransfected 1165 cells (lane 1) and from c-myc-(lanes 2-9) and HS1234 c-myc-(lanes 10-25) transfected clones. Transcripts initiating from P1 and P2 are indicated, and the signal from protected mouse GAPDH RNA is shown. Signals corresponding to protected RNA bands were quantitated by a PhosphorImager system. Total c-myc expression for each HS1234 c-myc clone was calculated as the sum of P1-and P2-initiated transcripts normalized to the mouse GAPDH level. $(B)$ Per copy expression of HS1234 c-myc clones was calculated as total expression divided by transfected DNA copy number, determined through Southern blot analysis (data not shown).

To compare the effects of HS12 to HS1234 and E $\mu$ on stable c-myc transcription in a Burkitt's lymphoma background, we transfected Raji cells with various c-myc constructs that had been cloned into the EBV-derived episomal vector, pHEBO (Sugden et al. 1985), shown in Figure $3 \mathrm{~A}$ and $\mathrm{B}$. Because the stably transfected c-myc genes on the episome do not become integrated into cellular DNA, the control c-myc genes are not subject to position effects. Thus, in contrast to the low frequency of active control c-myc integrants obtained by conventional stable transfection (see above), the episome system offers the advantage of providing large numbers of active control c-myc templates. This permits direct comparisons of expression and promoter usage between control and HS-driven c-myc constructs in the absence of position effects (Polack et al. 1991). RNA from pools of stably transfected Raji cells was analyzed for c-myc expression by S1 protection (Fig. 6A). Because the translocated c-myc allele in Raji has a large deletion at the end of exon 1 (Rabbitts et al. 1983), our S1 probe did not protect transcripts from this endogenous allele, allowing us to compare c-myc expression originating from the pHEBO constructs.

Consistent with previous reports that unrearranged c-myc alleles in Burkitt's lymphoma and plasmacytoma cells are generally inactive, we detected few P1 and P2 transcripts in untransfected Raji cells (Fig. 6A). When c-myc was expressed either without an additional enhancer or when linked to the mouse $3^{\prime} \mathrm{C} \alpha$ enhancer (HS12), transcripts initiated at P2 were predominant, resulting in a $\mathrm{P} 1 / \mathrm{P} 2$ ratio of 0.2 . In contrast, three independent pools of HS1234 c-myc transfectants exhibited elevated $\mathrm{P} 1 / \mathrm{P} 2$ ratios $\geqslant 1.0$, whereas $\mathrm{E} \mu$ increased the $\mathrm{P} 1 /$ $\mathrm{P} 2$ ratio to 0.8 .

As was observed in 1165 cells, per copy expression of c-myc in Raji pools containing HS1234 c-myc was significantly higher, 40 -fold, than that in pools containing the control c-myc construct. Linkage of the E $\mu$ enhancer or HS12 (3' $\mathrm{C} \alpha$ enhancer) to c-myc increased per copy expression to a lesser degree, with $\mathrm{E} \mu$ pools expressing 12-fold and HS12 pools expressing 3-fold more c-myc transcripts per DNA copy. A possible caveat in the per copy expression analysis of c-myc- and HS1234 c-myccontaining pools is the finding that episome copy numbers varied significantly between these pools. The copy number of three Raji pools independently transfected with the HS1234 c-myc construct was 15-fold lower than two pools expressing the control c-myc plasmid, whereas DNA copy numbers for the $\mathrm{E} \mu$ and HS12 pools were approximately half that of the control c-myc pools (see legend to Fig. 6). Thus, although the enhancement of c-myc expression by HS1234 in the stable Raji transfectants is consistent with the transient data, we cannot rule out the formal possibility that cells with high epi- 
A

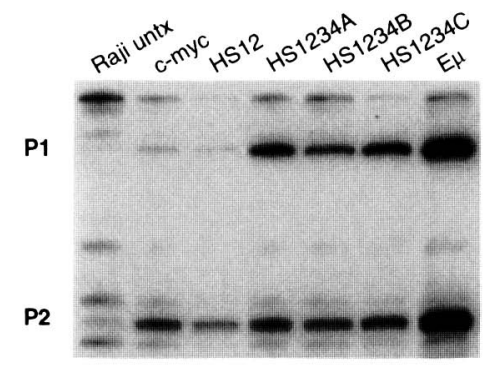

GAPDH
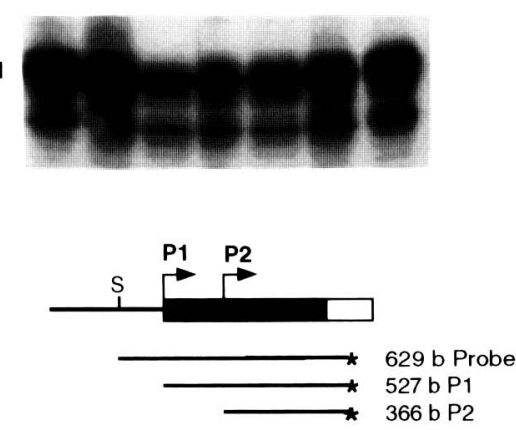

B

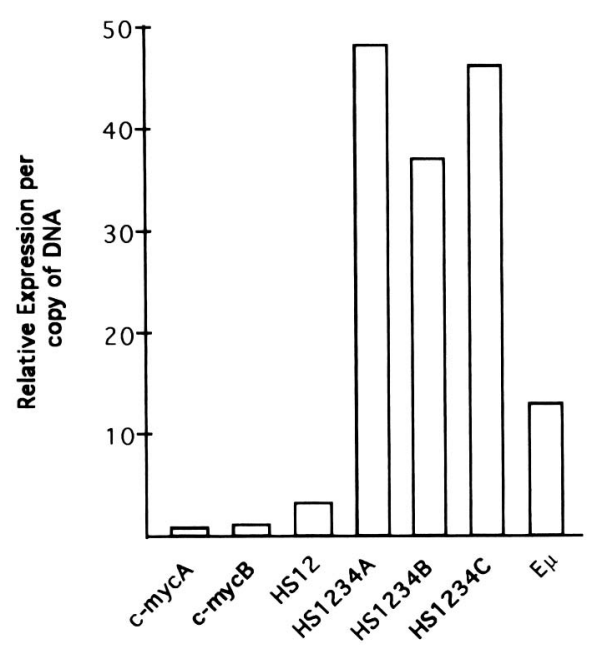

Figure 6. Expression of human c-myc from pHEBO constructs in Raji Burkitt's lymphoma cells. Raji Burkitt's lymphoma cells were stably transfected with an episomal vector, $\mathrm{pHEBO}$, containing human c-myc alone or linked to HS12, HS1234, or $\mathrm{E} \mu$. (A) Total RNA isolated from stable pools was analyzed in a S1 nuclease assay with an end-labeled single-stranded probe specific for c-myc transcripts originating from transfected DNAs. A diagram of human c-myc exon 1 is shown along with the deletion (open box), at the end of exon 1 present in the Raji-translocated c-myc allele. The location of the S1 probe and size of protected P1- and P2-initiated fragments are indicated. As an internal control, a probe specific for human GAPDH was also included in the assays. Transcripts initiating from P1 and P2 are indicated, and the signal from protected human GAPDH is shown. S1 analysis of three independently transfected pools is presented for the HS1234 c-myc pHEBO construct. $(B)$ Per copy expression of the stably transfected Raji pools was calculated as total P1 + P2 expression divided by transfected DNA copy number as determined by Southern blot analysis (data not shown). Episomal copy numbers of the various pools were estimated to be $c-m y c$ pools $A, B=190$ and $126 ; \mathrm{HS} 12$ pool =95, HS1234 pools $A, B, C=12,11$ and 8 ; $\mathrm{E} \mu \mathrm{pool}=69$.

some numbers may transcribe any one template less efficiently than cells with fewer episome numbers.

The cause of the relatively low number of stable episomes present in HS1234 c-myc containing pools is unclear. Because $\mathrm{E} \mu$ myc-containing pools transcribed more c-myc per cell than HS1234 c-myc pools, (based on relative levels of GAPDH control transcripts), a selection against high c-myc expression in HS1234 c-myc pools seems unlikely. Sequences within the HS1234 DNA fragment could inhibit transcription directly, by interfering with vector origin function, or indirectly, by comprising a competing origin in the plasmid. Alternatively, the high c-myc transcription from HS1234 c-myc episomes might itself inhibit replication of these episomes. Support for the latter hypothesis comes from a recent study in human cells in which high transcriptional activity of an autonomously replicating plasmid decreased the frequency of replication of that plasmid (Haase et al. 1994). The reduced episome numbers observed in HS1234 c-myc transfectants, then, could be a result of a highly active c-myc promoter in these constructs.

\section{HS1-4 alters the distribution of RNA polymerase II complexes in the c-myc gene in plasmacytoma and Burkitt's lymphoma cells}

Nuclear run-on analyses of normal c-myc genes have demonstrated that a conditional elongation block within exon 1 is a major mode of regulation of this gene (Bentley and Groudine 1986; Krumm et al. 1992; Strobl and Eick 1992). Previous nuclear run-on analyses of c-myc transcripts in Burkitt's lymphoma cells have revealed a constitutive increase in polymerase density in the $3^{\prime}$ region of the gene (Bentley and Groudine 1986; Cesarman et al. 1987; Strobl et al. 1993), indicating an abrogation of this control mechanism. Because linkage of HS1234 to c-myc was observed to affect many aspects of the gene's transcription, we sought to determine whether HS1234 directed an alteration in polymerase distribution along the transfected c-myc gene.

Nuclear run-on transcription experiments were performed on both plasmacytoma 1165 clones containing integrated c-myc or HS1234 c-myc and on pools of transfected Raji cells containing episomes with c-myc or HS1234 c-myc with exon 1- and intron 1-specific probes described previously (Spencer et al. 1990) (Fig. 7A). The hybridization signals, quantified by PhosphorImager, were corrected for the $U$ content of each probe and were normalized to the total exon $1+$ intron 1 signal to give a relative distribution of polymerases within these regions of the gene. Untransfected 1165 cells exhibited little detectable c-myc signal demonstrating the lack of cross-hybridization between murine c-myc and our human probes (Fig. 7B). Analysis of 1165 clone 1.2, which 
A

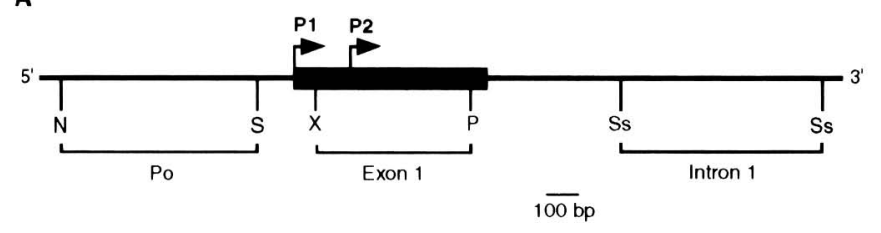

B

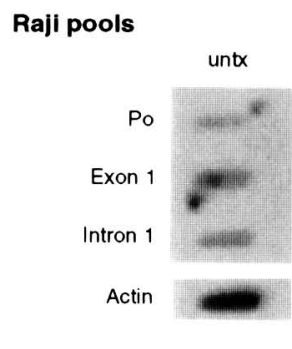

1165 clones

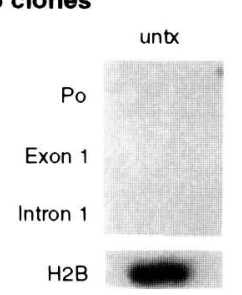

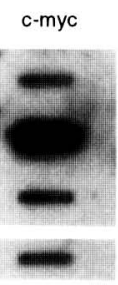
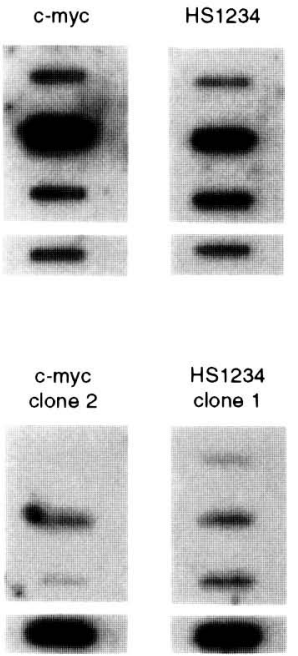

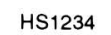

HS1234

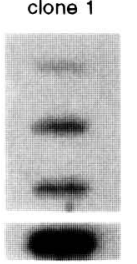

C

Relative number of polymerases in Intron1/ Exon1

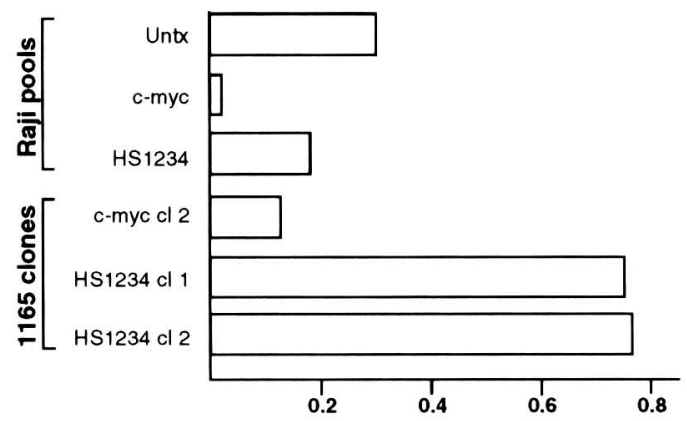

Figure 7. Nuclear run-on transcription analyses of 1165 plasmacytoma clones transfected with c-myc or HS1234 c-myc and Raji Burkitt's lymphoma cells transfected with the pHEBO c-myc, or HS1234 c-myc constructs. $(A)$ Position within the human c-myc gene of the antisense exon 1 and intron 1 probes used to detect RNA synthesized in nuclear run-ons. Control probes for actin or H2B were also included. $(B)$ Nuclei were isolated from 1165 clones and Raji cell pools stably transfected with the constructs indicated, and run-on assays were performed as described (see Materials and methods). (C) Ratio of polymerase complexes transcribing intron 1 to exon 1. Hybridization signals in $B$ were quantitated by a PhosphorImager system, and values, corrected for the uridine content of each probe, were normalized to the total exon $1+$ intron 1 signal (exon 1 probe contains 73 uridines and intron 1 probe contains 136 uridines). The graph depicts relative polymerase readthrough from exon 1 into intron 1 sequences.

expresses human c-myc, revealed a disproportionately low level of polymerase complexes in intron 1 compared with exon 1 as indicated by a corrected intron 1 to exon 1 signal ratio of 0.13 (Fig. 7 C). The intron $1 /$ exon 1 ratio was nearly six-fold higher in two different 1165 clones containing HS1234-linked c-myc, suggesting that significantly more polymerase complexes had transcribed farther $3^{\prime}$ into the transfected gene in these cells.

Similar analyses of the Raji-transfected pools revealed that murine HS1234 could also affect polymerase distribution along c-myc in a Burkitt's lymphoma background. Transcription of endogenous Raji c-myc was low compared with the pools containing the transfected c-myc episomes and the ratio of intron 1 to exon 1 signal was 0.30 , reflecting the absence of a significant disparity in polymerase density in the $5^{\prime}$ and $3^{\prime}$ regions of the gene. (Fig. 7B,C). Consistent with the above data from 1165 clones, c-myc-transfected Raji pools demonstrated a very low intron 1 /exon 1 signal ratio of 0.02 , whereas HS1234 c-myc Raji pools exhibited an eightfold increase in this ratio. In addition, linkage of the $\mathrm{E} \mu$ enhancer to c-myc resulted in a fivefold increase in polymerase density in intron 1 (data not shown). These results suggest that HS1234 and the E $\mu$ enhancer augment c-myc transcription, at least in part, by abrogation of transcriptional elongation control mechanisms.

\section{Discussion}

HS3 and HS4 define novel regulatory elements in the $3^{\prime}$ Ca $\lg H$ region

Several lines of evidence have suggested the presence of a regulatory element/domain in the region $3^{\prime}$ of the $\mathrm{IgH}$ $\mathrm{C} \alpha$-coding genes. Naturally occurring deletions of the intronic enhancer, $\mathrm{E} \mu$, do not impair heavy-chain expression in a number of characterized myeloma cell lines, whereas a large deletion of sequences $3^{\prime}$ to the $\mathrm{C} \alpha$ gene does reduce heavy-chain transcription. In addition, the deregulated expression of c-myc alleles translocated into the IgH locus cannot be attributed simply to $\mathrm{E} \mu$, as this enhancer is not linked to c-myc in murine plasmacytomas and is only occasionally linked to c-myc in human Burkitt's lymphomas. The recent discovery and functional analyses of two enhancers located 3' of $\mathrm{C} \alpha\left(3^{\prime} \mathrm{C} \alpha\right.$ 
enhancer, corresponding to HS12 described above, and $\mathrm{C} \alpha 3^{\prime}$ enhancer) support a role for the $3^{\prime} \mathrm{C} \alpha$ region sequences in the regulation of normal $\mathrm{IgH}$ gene expression, as well as in the deregulation of c-myc genes that become cis linked through genomic rearrangement. The results presented in this report demonstrate that two additional elements (HS3 and HS4), located 13 and $17 \mathrm{~kb} 3^{\prime}$ of the $3^{\prime} \mathrm{C} \alpha$ enhancer, likely contribute to the regulatory potential of the $3^{\prime} \mathrm{C} \alpha$ region.

Sequence analysis of the murine $3^{\prime} \mathrm{C} \alpha$ enhancer has revealed the presence of multiple protein-binding motifs which, through deletion experiments, have been shown to act synergistically to impart the enhancer with its transcriptional activity and tissue specificity (Grant et al. 1992). Similarly, HS3 and HS4 contain multiple binding sites for transcriptional activators commonly associated with immunoglobulin enhancers, and, like HS12 $13^{\prime}$ $\mathrm{C} \alpha$ enhancer), these elements activate the c-myc and $\mathrm{V} \lambda 1$ promoters in plasmacytoma cell transient assays. In combination, HS1234 directed a highly synergistic transcriptional response, equaling that induced by $E \mu$, on both the c-myc and $V \lambda 1$ promoters in plasmacytoma cell lines. The actual mechanism of the observed synergies is unknown. Multiple interactions are likely occurring between activating factors and some component(s) of the basic transcriptional machinery, either simultaneously or at distinct stages of preinitiation complex assembly (Lin et al. 1990; Choy and Green 1993; Herschlag and Johnson 1993).

The DNA encompassing HS4 as well as HS12 and HS3 has been determined to be hypermethylated at the pre-B stage, leading to the suggestion that a DNA-binding protein specific for methylated DNA might interact with the $3^{\prime} \mathrm{C} \alpha$ region to help sequester functional elements (Giannini et al. 1993). Alternatively, the DNA sequences comprising HS4 might bind positive acting factors at the pre-B stage despite being surrounded by methylated chromatin. In the latter scenario, a methylated DNAbinding protein might create an open window for a transacting factor to bind in an otherwise inaccessible region (Gross and Garrard 1988). In transient assays, we observed that HS4 can enhance transcription from both the $c-m y c$ and $V \lambda 1$ promoters in pre-B cells, suggesting that this region has the potential to contribute positively to transcription. Concordant with the DNase I HS data, HS12 and HS3 had no enhancer activity in pre-B cells.

Interestingly, the enhancing potential of HS4 on the $\mathrm{V} \lambda \mathrm{l}$ promoter, but not on the c-myc promoter, appeared to be influenced by the presence of HS12 in pre-B cells. HS12, the 3' C $\alpha$ enhancer, has been shown to bind NFHB (BSAP), a negative regulatory protein expressed in pro-, pre- and mature B cells (Singh and Birshtein 1993). Although we observed no reduction in the HS4 enhancer potential on the c-myc promoter by addition of HS12, this addition did reduce the activation from $\mathrm{V} \lambda 1$ by $50 \%$. This result suggests that promoter specific interactions between transcription complexes and proteins bound to upstream elements present in HS1-4 could add to the complexity of the potential of $\mathrm{HS} 1-4$ to regulate normal IgH gene expression.
Also in agreement with DNase I mapping data, none of the HS1-4 elements demonstrated enhancer activity in a fibroblast line, either alone or in combination. Motifs for several ubiquitously expressed helix-loop-helix DNAbinding proteins are present in each HS fragment, suggesting that the inactivity of HS1-4 in non-B cells could be mediated either through cell type-specific repressors or through the binding of $\mathrm{HLH}$ dimers having different composition and activity than those found in cells of the B lineage (Imler et al. 1987; Pongubala and Atchison 1991).

\section{HS1234 is sufficient to deregulate c-myc transcription}

In a recent study, linkage of c-myc to sequences encompassing the human Igא locus containing MAR, intron enhancer, constant $\kappa$ gene, and $3^{\prime}$ enhancer resulted in increased c-myc expression and a promoter shift from $\mathrm{P} 2$ to Pl from constructs stably transfected into Raji cells (Polack et al. 1993). The effects on c-myc transcription were dependent on an interaction between these elements, as neither enhancer alone was capable of inducing the altered pattern of $\mathrm{c}-\mathrm{myc}$ expression. These findings are consistent with the observation that all translocations between $c-m y c$ and the human $\kappa$ light-chain locus, $t(2 ; 8)$, result in colocalization of the $3^{\prime}$ and intron enhancers with c-myc on one of the rearranged chromosomes. In contrast, chromosomal rearrangements between $\mathrm{c}-\mathrm{myc}$ and the $\mathrm{IgH}$ locus generally segregate $\mathrm{E} \mu$ and the $3^{\prime}$ regulatory region, $\mathrm{HS} 1-4$, to different translocation products. Consistent with these findings, we have demonstrated that linkage of HS1234 to c-myc deregulates c-myc expression without the requirement of an additional interaction with the intron enhancer $\mathrm{E} \mu$. In stable transfection assays, sequences comprising HS1234 are sufficient to direct high level expression, a P2 to P1 promoter shift, and the deregulation of an important control of c-myc expression, transcriptional elongation. We are currently evaluating the contribution of individual HS elements to various aspects of the HS1234 c-myc expression phenotype.

In Raji Burkitt's lymphoma cells, linkage of the $\mathrm{E} \mu$ enhancer to $c-m y c$ resulted in many of the same changes in c-myc transcription as those induced by $\mathrm{HS} 1234$, including an increase in the elongation efficiency of RNA polymerase II through the c-myc gene. Thus, it is possible that various classes of enhancers, including HS1234 and $\mathrm{E} \mu$, may increase gene expression, at least in part, by contributing to the assembly of RNA transcription complexes that are highly efficient in elongation (for review, see Krumm et al. 1993; Yankulov et al. 1994).

\section{HS1234 functions as an LCR}

HS1234 linked c-myc constructs are expressed in a plasmacytoma line at levels proportional to DNA copy number. c-myc expression was observed in all subclones containing HS1234 constructs, but in only one subclone containing the control c-myc gene, suggesting that HS1234 either can confer position-independent expres- 
sion to a linked gene in these cells, or can overcome the postulated allelic exclusion of unrearranged c-myc genes in plasmacytoma cells. The pleiotropic effects of HS1234 on c-myc expression are reminiscent of a class of transcriptional regulatory elements referred to as LCRs. LCRs have been defined functionally by their ability to direct tissue-specific expression of linked genes in a position independent, copy number dependent manner. The $\beta$-globin LCR, which regulates the tissue and temporal expression of the $\beta$-like globin genes throughout development, influences both the chromatin organization of the globin locus and the expression of stage-specific globin gene promoters. By analogy, an LCR-like element composed of sequences spanning HS1-4 in the IgH 3' $\mathrm{C} \alpha$ region may function in normal B cells to maintain the IgH constant genes in a transcriptionally competent chromatin structure, as well as to regulate the class switching of constant genes through interactions with their specific promoters.

Recently, it was reported that the targeted deletion of HS12 ( 3 ' C $\alpha$ enhancer) and concomitant insertion of a selectable marker gene into this region resulted in particular class switching defects of IgH isotypes /Cogné et al. 1994). It is not clear whether these defects are the result of the deletion of HS12 per se or of a selectable marker-mediated promoter/enhancer competition for other elements in the $3^{\prime} \mathrm{C} \alpha$ region, as has been observed for targeted insertions in the $\beta$-globin LCR (Kim et al. 1992). Nevertheless, the fact that only a subset of isotypes was affected by the deletion/insertion event is consistent with a model in which all four HSs in the $3^{\prime} \mathrm{C} \alpha$ region interact to maintain a chromatin domain permissive for IgH constant gene expression and suggests some specificity or competition in interactions between various constant gene promoters and $3^{\prime}$ regulatory elements. Additional targeted deletion studies will be required to further delineate the role of individual elements in the $3^{\prime}$ $\mathrm{C} \alpha$ region in regulating the tissue- and stage-specific expression of genes in the IgH locus.

\section{Materials and methods}

\section{DNase I hypersensitive site assays}

The isolation and DNase I treatment of nuclei were performed as described (Forrester et al. 1990). Briefly, nuclei were incubated with $0.01-15 \mathrm{mg} / \mathrm{ml}$ of DNase I at $37^{\circ} \mathrm{C}$ for $5-15 \mathrm{~min}$ before being lysed and treated with proteinase $\mathrm{K}$ in $2 \times$ stop buffer $(0.6 \mathrm{M} \mathrm{NaCl}, 20 \mathrm{~mm}$ Tris- $\mathrm{HCl}(\mathrm{pH} 7.6), 10 \mathrm{~mm}$ EDTA, $1 \%$ SDS|. DNA was precipitated, treated with RNase A, phenol/ chloroform extracted, and reprecipitated prior to restriction enzyme digestion and southern blot analysis. Preliminary characterization of HS12 was done on XbaI-digested DNA with the 500-bp EcoRI-XbaI fragment indicated in Figure 1 as a Southern blot hybridization probe. HS3 and HS4 were initially mapped with the same probe on blots of EcoRI-digested DNA.

\section{HS cloning and sequencing}

Approximately $30 \mathrm{~kb}$ of mouse genomic sequence spanning the $3^{\prime} \mathrm{C} \alpha$ enhancer was cloned in sequential steps from a phage library of partially digested 129 ES genomic DNA (Stratagene).
Initial hybridization screening was done with a $1.1-\mathrm{kb}$ Stul fragment from the rat $3^{\prime} \mathrm{C} \alpha$ region (gift from Dr. M. Neuberger). Library screening and subsequent mapping of positive phage were performed by use of standard molecular biology techniques (Ausubel et al. 1989). Southern blot analyses of MPC-11 DNA that had been DNase I-treated and restriction digested with $X b a I$ and HindIII localized HS3 to a 1182-bp XbaI-Sau3A fragment (by use of 280-bp HindIII-BamHI fragment as a hybridization probe) and HS4 to a 1381-bp PstI-HindIII fragment lusing the 1182-bp Xba1-Sau3A fragment as a hybridization probe). These fragments were subcloned from a positive phage into pBSKSII + vector (Stratagene) for propagation and were sequenced by the dideoxy chain termination method with the Sequenase version 2.0 sequencing kit and protocol.

\section{Plasmid constructs}

Mouse genomic DNA fragments containing HS1-4 were subcloned from positive phage isolated from a 129 ES genomic library. HS1 and HS2 lie within the $3^{\prime} \mathrm{C} \alpha$ enhancer (Giannini et al. 1993) and are contained in a 4-kb XbaI fragment. HS3 maps to a 1182 -bp $X b a I-S a u 3 A$ fragment that was subcloned as a slightly larger $\mathrm{XbaI}-\mathrm{SalI}$ fragment (SalI site was picked up from the phage polylinker). HS4 is contained in a 1381-bp PstIHindIII fragment. Restriction fragments encompassing the individual HS sites were subcloned singly and in combinations into the pBSKSII + vector while maintaining their genomic order and $5^{\prime}-3^{\prime}$ orientation.

The human growth hormone ( $\mathrm{HGH}$ ) constructs used in transient assays were derived from $\mathrm{pOGH}$, a $\mathrm{pUCl} 2$ vector containing a promoterless $\mathrm{HGH}$ gene. A $2.5-\mathrm{kb}$ HindIII-NaeI fragment encoding the human c-myc upstream region, promoter and first half of exon 1 was cloned $5^{\prime}$ of the HGH gene to create the enhancerless control plasmid, c-mycGH. Similarly, a 161-bp SacI-SspI fragment comprising the $\mathrm{V} \lambda \mathrm{l}$ promoter (Hagman et al. 1990) was used to generate Vג IGH. Various individual and combined HS fragments were then cloned immediately $5^{\prime}$ to the $c-m y c$ and $V \lambda 1$ promoters by use of restriction sites acquired from the pBSKSII + vector and those present in the polylinker of pOGH. The orientation of the HS fragments to the c-myc and V $\lambda 1$ promoters was $5^{\prime} \rightarrow 5^{\prime}$ (i.e., the c-myc HindIII $5^{\prime}$ end adjoined the $5^{\prime}$-most $\mathrm{XbaI}$ end of the HS12 fragment in HS1234). A 1-kb fragment containing the murine $E \mu$ enhancer and flanking MAR sequences (Cockerill et al. 1987) was also cloned upstream of the two promoters to generate $\mathrm{E} \mu$-c-mycGH and $\mathrm{E} \mu$ $\mathrm{V} \lambda 1 \mathrm{GH}$.

The HS1234 c-myc construct used to stably transfect mouse plasmacytoma 1165 cells was made by initially subcloning a 8.1-kb HindIII-EcoRI fragment containing human c-myc 5'-untranscribed and coding sequences into the vector pBSKSII + at the HindIII and EcoRI sites. A 6.5-kb fragment generated by NotI digestion, followed by nucleotide fill-in and SalI digestion, comprising HSl -4 was then inserted immediately upstream of c-myc into a site created by HindIII digestion, followed by fill-in and Sall digestion.

The episomal vector, $\mathrm{pHEBO}$, contains the EBV origin of latent replication oriP and the hygromycin $B$ resistance gene (Sugden et al. 1985). The 8.1-kb HindIII-EcoRI c-myc-encoding fragment was cloned into HindIII and BamHI sites, placing c-myc 5' to oriP. Fragments containing HS12, HS1234, and E $\mu$ were then inserted immediately upstream of $c-m y c$ in pHEBO, by use of restriction sites acquired from the corresponding $c$-mycGH transient constructs.

\section{Cell lines and transfections}

The Raji Burkitt's lymphoma cell line (Rabbitts et al. 1983), 
obtained from Dr. R. Baer (University of Texas), and the mouse MPC-11 plasmacytoma cell line (Stanton et al. 1984) were maintained in RPMI 1640 containing $10 \%$ fetal bovine serum, 2 $\mathrm{mM}$ glutamine and $50 \mathrm{mM}$ 2-mercaptoethanol. The TEPC 1165 mouse plasmacytoma line (Yang et al. 1985) was obtained from Dr. R. Nordan (National Institutes of Health, Bethesda, MD) and was grown in the same media as above supplemented with 100 PCT-GF units of recombinant Il-6 per milliliter of media (generous gift of R. Nordan). The mouse pre-B lymphocyte cell line 18-81 and the mouse L-cell fibroblast lines were cultured in Dulbecco's modified Eagle medium (DMEM) with $10 \%$ bovine calf serum and $2 \mathrm{mM}$ glutamine.

TEPC 1165, MPC-11, 18-81, and L-cells were transiently transfected with $\mathrm{HGH}$ constructs by electroporation. Typically, $6 \times 10^{6}$ cells in serum-free DMEM were electroporated with $4 \mu \mathrm{g}$ of control plasmid, pCMV $\beta$-GAL, and 5-30 $\mu \mathrm{g}$ of reporter $\mathrm{HGH}$ plasmid. Transfections with the VXl promoter constructs were done with less reporter DNA because of the considerable unenhanced activity of this promoter in some of the cell lines tested. Approximately $48 \mathrm{hr}$ after electroporation, cell supernatants were assayed for growth hormone content by use of the Allegro HGH transient gene expression system (Nichols Institute Diagnostics) following the manufacturer's protocol. At the same time, cell pellets were assayed for $\beta$-gal activity (Roederer et al. 1991). HGH levels expressed by the various HS constructs were normalized for the $\beta$-gal-determined transfection efficiencies, and relative transcription values were calculated relative to the enhancerless c-mycGH and VגIGH control plasmids. The data in Figure 4 are presented such that the activity of the enhancerless control (promoter only) is equal to 1 .

Mouse plasmacytoma 1165 cells were stably transfected by electroporation of $10^{7}$ cells in serum-free DMEM with $5 \mu \mathrm{g}$ of linearized pRSV-Neo (Gorman et al. 1983) and $30 \mu \mathrm{g}$ of linearized c-myc or HS1234 c-myc plasmid. Transfected cells were plated immediately into wells at low density to obtain clones following G418 selection ( $1.5 \mathrm{mg} / \mathrm{ml}$ for $2-4$ weeks). Raji Burkitt's lymphoma cells were stably transfected with pHEBO derived constructs by electroporating $10^{7}$ cells with $40 \mu \mathrm{g}$ of circular DNA. Stably transfected pools were established by selection in $1 \mathrm{mg} / \mathrm{ml}$ of hygromycin for 2 weeks.

\section{DNA and RNA isolation and analyses}

Total cellular DNA was isolated by standard techniques (Ausubel et al. 1989|, and copy numbers of transfected clones and pools were determined by Southern blot analyses of $\mathrm{XhoI}$ and Xbal-digested DNA (1165 clones) or XbaI-digested DNA (Raji pools) with the 1113 -bp Xhol-Xbal human c-myc fragment as a probe. Hybridization signals were quantitated with a PhosphorImager system.

Total RNA for S1 protection assays was isolated from cell clones and pools with RNAzol (Cinna/Biotecx) following the supplied protocol. 5'-End-labeled S1 nuclease probes were generated by Sequenase (U.S. Biochemical) extension of phosphorylated oligonucleotides that previously had been annealed to single-stranded M13 c-myc templates. The double-stranded, extended DNA, was digested with $S m a I$, and end-labeled singlestranded fragments were isolated on $6 \%$ acrylamide-urea gels. Oligonucleotides used as extension primers for human c-mycspecific probes included a 32-mer complementary to the c-myc coding strand from positions +270 to +302 relative to the P1 initiation site ( 1165 clonal analysis) and a 22 -mer complementary to sequences +505 to +527 relative to P1 (Raji pools analysis).

The human GAPDH S1 probe was generated by unidirectional PCR on a linearized template by use of a phosphorylated primer complementary to GAPDH exon 1 sequences. Briefly, a plasmid containing the 548-bp HindIII-XbaI fragment from human GAPDH exon 1 was restriction enzyme digested to create a linear template that contained $75 \mathrm{bp}$ of vector sequence upstream of the GAPDH sequence. One hundred nanograms of a kinased 20-mer complementary to GAPDH sequences +80 to +100 (relative to the HindIII site) and $5 \mu \mathrm{g}$ of template DNA were heated to $94^{\circ} \mathrm{C}$ for $10 \mathrm{~min}$ and used in an eight-cycle PCR reaction. End-labeled single-stranded PCR products were purified on $6 \%$ acrylamide-urea gels. The mouse GAPDH $S 1$ probe was an end-labeled 73-base oligonucleotide that has a 60-base identity to the mouse GAPDH antisense strand.

S1 assays were performed essentially as described (Spencer et al. 1990) with $40 \mu \mathrm{g}$ of total RNA and $1-5 \times 10^{4}$ to cpm of singlestranded probes. S1-Protected fragments were resolved on denaturing acrylamide-urea gels and signals were quantitated with a PhosphorImager system. Total expression of c-myc constructs stably transfected into 1165 and Raji cells was calculated as the sum of P1- and P2-initiated transcripts normalized to the level of the GAPDH control transcripts.

\section{Nuclear run-on assays}

Isolation of nuclei and high salt $(150 \mathrm{~mm} \mathrm{KCl})$ nuclear run-on assays were performed as described (Bentley and Groudine 1986; Krumm et al. 1992). [ $\alpha{ }^{-32}$ P]UTP-Labeled run-on transcription products were column purified and hybridized to excess c-myc single-stranded antisense DNA that had been bound to GeneScreen Plus membranes. Filters were treated with RNase $A$ and washed as described previously. PhosphorImager quantitated signals were corrected for the uridine content of the c-myc exon 1 probe (a 446-base Xhol-PvuII fragment containing 73 uridines that extends from +66 to +512 ) and the c-myc intron 1 probe (a 606-base SacI fragment with 136 uridines that extends from +940 to +1546 ). Nucleotide positions are given relative to the $\mathrm{Pl}$ initiation site.

\section{Acknowledgments}

We thank our colleagues in the Groudine laboratory and at the Hutchinson Center for their comments during the course of these experiments and for critical reading of this manuscript. In addition, we thank Barbara Birshtein and Jennifer Michaelson for stimulating discussions on B cell maturation and for sharing their unpublished observations regarding transient activity of $3^{\prime}$ $\mathrm{C} \alpha$ sequences. We gratefully acknowledge Richard Nordan for providing us with recombinant IL-6 protein. This work was supported by National Cancer Institute grants CA54337 and CA57156 to M.G. and by National Institutes of Health grant CA09437.

The publication costs of this article were defrayed in part by payment of page charges. This article must therefore be hereby marked "advertisement" in accordance with 18 USC section 1734 solely to indicate this fact.

\section{References}

Aguilera R.J., T.J. Hope, and H. Sakano. 1985. Characterization of immunoglobulin enhancer deletions in murine plasmacytomas. EMBO / 4: 3689-3693.

Ausubel, F.M., R. Brent, R.E. Kingston, D.D. Moore, J.G. Seidman, J.A. Smith, K. Struhl. 1989. Current protocols in molecular biology. Greene Publishing Associates/Wiley Interscience, New York.

Beckmann, H., L.-K. Su, and T. Kadesch. 1990. TFE3: A helix- 
loop-helix protein that activates transcription through the immunoglobulin enhancer $\mu \mathrm{E} 3$ motif. Genes \& Dev. 4: 167179.

Bentley, D.L. and M. Groudine. 1986. Novel promoter upstream of the human c-myc gene and regulation of c-myc expression in B cell lymphomas. Mol. Cell. Biol. 6: 3481-3489.

Bernard, O., S. Cory, S. Gerondakis, E. Webb, and J.M. Adams. 1983. Sequence of the murine and human cellular myc oncogenes and two modes of myc transcription resulting from chromosome translocation in B lymphoid tumors. EMBO $\mathrm{J}$. 2: $2375-2383$.

Blom van Assendelft, G., O. Hanscombe, F. Grosveld, and D.R. Greaves. 1989. The $\beta$-globin dominant control region activates homologous and heterologous promoters in a tissue specific manner. Cell 56: 969-977.

Cesarman, E., R. Dalla-Favera, D. Bentley, and M. Groudine. 1987. Mutations in the first exon are associated with altered transcription of c-myc in Burkitt lymphoma. Science 238: 1272-1275.

Choy, B. and M.R. Green. 1993. Eukaryotic activators function during multiple steps of preinitiation complex assembly. Nature 366: 531-536.

Cockerill, P.N., M.-H. Yuen, and W.T. Garrard. 1987. The enhancer of the immunoglobulin heavy chain locus is flanked by presumptive chromosomal loop anchorage elements. $J$. Biol. Chem. 262: 5394-5397.

Cogné, M., R. Lansford, A. Bottaro, J. Zhang, J. Gorman, F. Young, H.-L. Cheng, and F.W. Alt. 1994. A class switch control region at the $3^{\prime}$ end of the immunoglobulin heavy chain locus. Cell 77: 737-747.

Cory, S. 1986. Activation of cellular oncogenes in hemopoietic cells by chromosome translocation. Adv. Cancer Res. 47: 189-234.

Dariavach, P., G.T. Williams, K. Campbell, S. Pettersson, and M. Neuberger. 1991. The mouse IgH 3'-enhancer. Eur. I. Immunol. 21: 1499-1504.

Denny, C.T., G.F. Hollis, I.T. Magrath, and I.R. Kirsch. 1985. Burkitt lymphoma cell line carrying a variant translocation creates new DNA at the breakpoint and violates the hierarchy of immunoglobulin gene rearrangement. Mol. Cell. Biol. 5: 3199-3207.

Eckhardt, L.A. and B.K. Birshtein. 1985. Independent immunoglobulin class-switch events occurring in a single myeloma cell line. Mol. Cell. Biol. 5: 856-868.

Eick, D. and G.W. Bornkamm. 1989. Expression of normal and translocated c-myc alleles in Burkitt's lymphoma cells: Evidence for different regulation. EMBO J. 8: 1965-1972.

Forrester, W.C., E. Epner, M.C. Driscoll, T. Enver, M. Brice, T. Papayannopoulou, and M. Groudine. 1990. A deletion of the human $\beta$-globin locus activation region causes a major alteration in chromatin structure and replication across the entire $\beta$-globin locus. Genes \& Dev. 4: 1637-1649.

Giannini, S.L., M. Singh, C.-F. Calvo, G.F. Ding, and B.K. Birshtein. 1993. DNA regions flanking the mouse Ig 3' $\alpha$ enhancer are differentially methylated and DNaseI hypersensitive during B cell differentiation. I. Immunol. 150: 1772-1780.

Gorman, C.R., R. Padmanabdhan, and B. Howard. 1983. High efficiency DNA-mediated transformation of primate cells. Science 221: 551-553.

Grant, P.A., V. Arulampalam, L. Ahrlund-Richter, and S. Pettersson. 1992. Identification of ets-like lymphoid specific elements within the immunoglobulin heavy chain $3^{\prime}$ enhancer. Nucleic Acids Res. 20: 4401-4408.

Gregor, P.D. and S.L. Morrison. 1986. Myeloma mutant with a novel 3' flanking region: Loss of normal sequence and insertion of repetitive elements leads to decreased transcription but normal processing of the alpha-heavy chain gene products. Mol. Cell. Biol. 6: 1903-1916.

Gross, D.S. and W.T. Garrard. 1988. Nuclease hypersensitivity sites in chromatin. Annu. Rev. Biochem. 57: 159-197.

Grosveld, F., G. Blom van Assendelft, D. Greaves, and G. Kollias. 1987. Position-independent, high level expression of the human $\beta$-globin gene in transgenic mice. Cell 51: 975-985.

Haase, S.B., S.S. Heinzel, and M.P. Calos. 1994. Transcription inhibits the replication of autonomously replicating plasmids in human cells. Mol. Cell. Biol. 14: 2516-2524.

Hagman, J., C.M. Rudin, D. Haasch, D. Chaplin, and U. Storb. 1990. A novel enhancer in the immunoglobulin $\lambda$ locus is duplicated and functionally independent of $\mathrm{NF}_{\kappa} \mathrm{B}$. Genes \& Dev. 4: 978-992.

Herschlag, D. and F.B. Johnson. 1993. Synergism in transcriptional activation: A kinetic view. Genes \& Dev. 7: 173-179.

Imler, J.-L., C. Lemaire, C. Wasylyk, and B. Wasylyk. 1987. Negative regulation contributes to tissue specificity of the immunoglobulin heavy-chain enhancer. Mol. Cell. Biol. 7: 2558-2567.

Kim, C.G., E.M. Epner, W.C. Forrester, and M. Groudine. 1992. Inactivation of the $\beta$-globin gene by targeted insertion into the $\beta$-globin locus control region. Genes \& Dev. 6: 928-938.

Klein, S., F. Sablitsky, and A. Radbruch. 1984. Deletion of the $\mathrm{IgH}$ enhancer does not reduce immunoglobulin heavy chain production of a hybridoma IgD class switch variant. EMBO I. 3: 2473-2476.

Krumm, A., T. Meulia, M. Brunvand, and M. Groudine. 1992. The block to transcriptional elongation within the human c-myc gene is determined in the promoter-proximal region. Genes \& Dev. 6: 2201-2213.

Krumm, A., T. Meulia, and M. Groudine. 1993. Common mechanisms for the control of eukaryotic transcriptional elongation. BioEssays 15: 659-665.

Lieberson, R., S.L. Giannini, B.K. Birshtein, and L.A. Eckhardt. 1991. An enhancer at the $3^{\prime}$ end of the mouse immunoglobulin heavy chain locus. Nucleic Acids Res. 19: 933-937.

Lin, Y.-S., M. Carey, M. Ptashne, and M.R. Green. 1990. How different eukaryotic transcriptional activators can cooperate promiscuously. Nature 345: 359-361.

Magrath, I. 1990. The pathogenesis of Burkitt's lymphoma. Adv. Cancer Res. 55: 133-270.

Matthias, P. and D. Baltimore. 1993. The immunoglobulin heavy chain locus contains another B-cell-specific $3^{\prime}$ enhancer close to the $\alpha$ constant region. Mol. Cell. Biol. 13: 1547-1553.

Meyer, K.B. and M.S. Neuberger. 1989. The immunoglobulin $\kappa$ locus contains a second, stronger B-cell-specific enhancer which is located downstream of the constant region. EMBO I. 8: 1959-1964.

Nishikura, K., A. Ar-Rushdi, J. Erikson, R. Watt, G. Rovera, and C.M. Croce. 1983. Differential expression of the normal and of the translocated human c-myc oncogenes in B cells. Proc. Natl. Acad. Sci. 80: 4822-4826.

Pettersson, S., G.P. Cook, M. Bruggemann, G.T. Williams, and M.S. Neuberger. 1990. A second B-cell specific enhancer 3' of the immunoglobulin heavy chain locus. Nature 344: 165168.

Polack, A., L. Strobl, R. Feederle, M. Schweizer, E. Kock, D. Eick, H. Wiegand, and G.W. Bornkamm. 1991. The intron enhancer of the immunoglobulin kappa gene activates c-myc but does not induce the Burkitt-specific promoter shift. Oncogene 6: 2959-2964.

Polack, A., R. Feederle, G. Klobeck, and K. Hortnagel. 1993. Regulatory elements in the immunoglobulin kappa locus induce c-myc activation and the promoter shift in Burkitt's 
lymphoma cells. EMBO I. 12: 3913-3920.

Pongubala, J.M.R. and M.L. Atchison. 1991. Functional characterization of the developmentally controlled immunoglobulin kappa 3' enhancer: Regulation by Id, a repressor of helixloop-helix transcription factors. Mol. Cell. Biol. 11: 10401047.

Rabbitts, T.H., P.H. Hamlyn, and R. Baer. 1983. Altered nucleotide sequences of a translocated c-myc gene in Burkitt lymphoma. Nature 306: 760-765.

Richman, A. and A. Hayday. 1989. Normal expression of a rearranged and mutated c-myc oncogene after transfection into fibroblasts. Science 246: 494-497.

Roederer, M., S. Fiering, and L.A. Herzenberg. 1991. Facs-Gal: Flow cytometric analysis and sorting of cells expressing reporter gene constructs. Methods Enzymol. 2: 248-260.

Ruezinsky, D., H. Beckmann, and T. Kadesch. 1991. Modulation of the IgH enhancer's cell type specificity through a genetic switch. Genes \& Dev. 5: 29-37.

Singh, M. and B.K. Birshtein. 1993. NF-HB(BSAP) is a repressor of the murine immunoglobulin heavy chain $3^{\prime} \alpha$ enhancer at early stages of B-cell differentiation. Mol. Cell. Biol. 13: $3611-3622$.

Spencer, C.A. and M. Groudine. 1991. Control of c-myc regulation in normal and neoplastic cells. Adv. Cancer Res. 56: 148.

Spencer C.A., R.C. LeStrange, U. Novak, W.S. Hayward, and M. Groudine. 1990. The block to transcription elongation is promoter dependent in normal and Burkitt's lymphoma c-myc alleles. Genes \& Dev. 4: 75-88.

Stanton, L.W., J.Q. Yang, L.A. Eckhardt, L.J. Harris, B.K. Birshtein, and K.B. Marcu. 1984. Products of a reciprocal chromosome translocation involving the c-myc gene in a murine plasmacytoma. Proc. Natl. Acad. Sci. 81: 829-833.

Strobl, L.J. and D. Eick. 1992. Hold back of RNA polymerase II at the transcription start site mediates down regulation of c-myc in vivo. EMBO I. 11:3307-3314.

Strobl, L.J., F. Kohlhuber, J. Mautner, A. Polack, and D. Eick. 1993. Absence of a paused transcription complex from the c-myc $\mathrm{P} 2$ promoter of the translocation chromosome in Burkitt's lymphoma cells: implication for the c-myc P1/P2 promoter shift. Oncogene 8: 1437-1447.

Sugden, B., K. Marsh, and J. Yates. 1985. A vector that replicates as a plasmid and can be efficiently selected in B-lymphoblasts transformed by Epstein Barr virus. Mol. Cell. Biol. 5: $410-413$.

Taub, R., C. Moulding, J. Battey, W. Murphy, T. Vasicek, G. M. Lenoir, and P. Leder. 1984. Activation and somatic mutation of the translocated c-myc gene in Burkitt lymphoma cells. Cell 36: 339-348.

Townes, T.M. and R.R. Behringer. 1990. Human globin locus activation region (LAR): Role in temporal control. Trends Genet. 6: 219-233.

Yang, J.Q., S.R. Bauer, J.F. Mushinski, and K.B. Marcu. 1985. Chromosome translocations clustered $5^{\prime}$ of the murine c-myc gene qualitatively affect promoter usage: Implications for the site of normal c-myc regulation. EMBO I. 4: 14411447.

Yankulov, K., J. Blau, T. Purton, S. Roberts, and D.L. Bentley. 1994. Transcriptional elongation by RNA polymerase II is stimulated by transactivators. Cell 77: 749-759. 


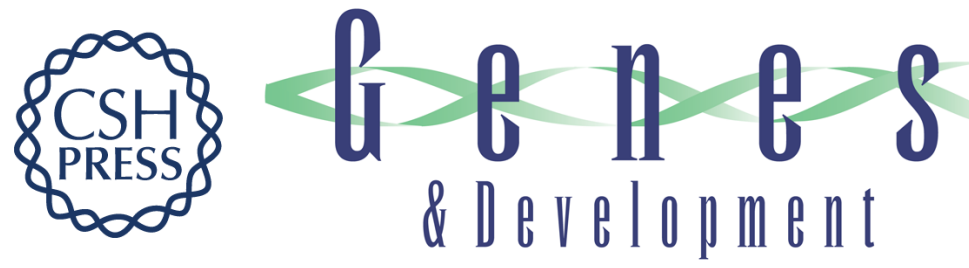

\section{Identification of a locus control region in the immunoglobulin heavy-chain locus that deregulates c-myc expression in plasmacytoma and Burkitt's lymphoma cells.}

L Madisen and M Groudine

Genes Dev. 1994, 8:

Access the most recent version at doi:10.1101/gad.8.18.2212

References This article cites 54 articles, 25 of which can be accessed free at:

http://genesdev.cshlp.org/content/8/18/2212.full.html\#ref-list-1

License

Email Alerting Service

Receive free email alerts when new articles cite this article - sign up in the box at the top right corner of the article or click here.

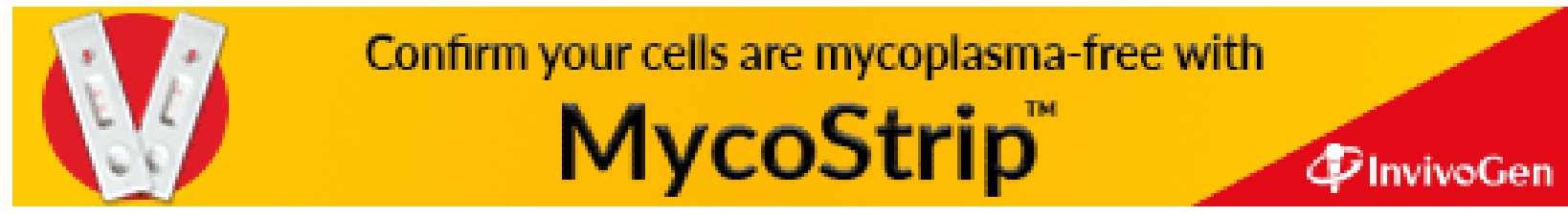

